\title{
Phân lập và tuyển chọn các chủng xạ khuẩn tại tỉnh Lâm Đồng có hoạt tính kháng Pythium vexans gây bệnh thối rễ trên rau ăn lá họ thập tự
}

\section{Screening and identification Streptomyces spp. of Lam Dong Province which can suppress root rot Pythium vexans fungus in cruciferous vegetables}

Đinh Anh Hòa ${ }^{1 *}$, Nguyễn Thị Ánh Nguyệt ${ }^{1}$, Lê Thị Mai Châm ${ }^{1}$, Trần Thùy Trang ${ }^{1}$, Trần Thị Phấn ${ }^{1}$, Hà Thị Loan ${ }^{1}$

${ }^{1}$ Trung tâm công nghệ sinh học TP.HCM, Việt Nam

*Tác giả liên hệ, Email: dinhanhhoa.ahi@gmail.com

THÔNG TIN
DOI:10.46223/HCMCOUJS.
tech.vi.16.1.1727.2021
Ngày nhận: 24/03/2021
Ngày nhận lại: 23/04/2021
Duyệt đăng: 29/04/2021
Tì khóa:
hoạt chất sinh học; pythium
vexans; streptomyces;
streptomyces filamentosus; thối
rễ

\section{TÓM TÁT}

DOI:10.46223/HCMCOUJS. tech.vi.16.1.1727.2021

Ngày nhận: 24/03/2021

Ngày nhận lại: 23/04/202
Nấm Pythium vexans là một trong những tác nhân lớn gây ra bệnh thối rễ và ức chế cây rau phát triển. Hiện nay, nghiên cứu ứng dụng chế phẩm sinh học trong kiểm soát, phòng trừ nấm gây hại đang ngày càng được quan tâm trong chiến lược phát triển một nền nông nghiệp sạch và bền vững. Nhiều loài xạ khuẩn thuộc chi Streptomyces được đánh giá là an toàn cho con người cũng như cây trồng, có khả năng ức chế sự phát triển của nhiều loại nấm gây bệnh ở cây trồng nhờ tiết ra một số hoạt chất sinh học. Trong nghiên cứu này, chúng tôi đã phân lập được 20 chủng xạ khuẩn từ 15 mẫu đất tại các vườn trồng rau ở tỉnh Lâm Đồng. Trong đó, chủng Streptomyces LD5.4 được đánh giá có hiệu quả ức chế cao nhất đối với nấm Pythium vexans $(51.80 \%)$, sau $48 \mathrm{~h}$ bằng phương pháp khuếch tán đĩa trên môi trường Potato Dextrose Agar (PDA) ở nhiệt độ phòng. Dựa trên đặc điểm hình thái và trình tự $16 \mathrm{~S}$ rRNA, chủng xạ khuẩn LD5.4 được xác định thuộc loài Streptomyces filamentosus. Với những đặc tính này, chủng Streptomyces filamentosus LD5.4 có tiềm năng ứng dụng vào sản xuất chế phẩm sinh học ức chế bệnh thối rễ trên rau ăn lá họ thập tự do nấm Pythium vexans gây ra.

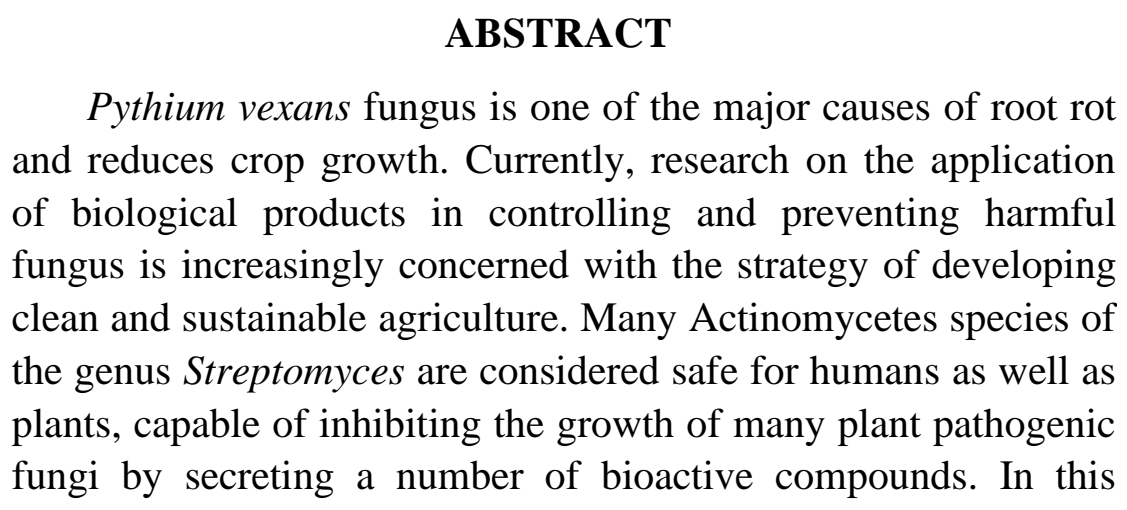


Keywords:

bioactive compounds; pythium vexans; root rot; streptomyces; streptomyces filamentosus study, from 15 soil samples of vegetable gardens in Lam Dong province, 20 strains of Streptomyces spp. were isolated. Of 20 isolates, the strain Streptomyces LD5.4 was rated with the highest inhibitory effect on the fungus, which can suppress root rot Pythium vexans fungus in cruciferous vegetables, reached $51.80 \%$, after 48 hours by disc diffusion method on Potato Dextrose Agar (PDA) environment at room temperature. Based on morphological characteristics and 16S rRNA sequence, Streptomyces sp. LD5.4 was determined to belong to the species Streptomyces filamentosus. With these properties, strain Streptomyces filamentosus LD5.4 has the potential to be used in the production of probiotics against root rot in Cruciferous vegetables, which is caused by Pythium vexans.

\section{Giới thiệu}

Việt Nam là một nước nông nghiệp, có khí hậu nhiệt đới nóng ẩm, mưa nhiều rất thuận lợi cho các Vi Sinh Vật (VSV) phát triển, trong đó có các VSV và nấm gây hại trên nông phẩm nói chung và rau màu nói riêng. Hiện nay, Lâm Đồng là tỉnh trồng rất nhiều hoa màu khác nhau, phổ biết nhất là cây họ rau họ thập tự cung cấp thực phẩm xanh cho các chợ đầu mối lớn như TP Đà Lạt, TP. HCM, Nha Trang, Đồng Nai và các chợ nhỏ lân cận. Tuy nhiên, rau họ thập tự có chu kỳ sống ngắn, cộng với điều kiện phát triển có ẩm độ cao nên rất dễ bị vi sinh vật xâm nhiễm và gây bệnh. Trong đó, nguyên nhân gây hại nghiêm trọng nhất là bệnh thối rễ do nấm Pythium vexans. Bệnh rất khó phòng trừ, cây có thể chết vài ngày sau khi nhiễm bệnh bởi vì tác nhân gây bệnh có thể lây lan theo nguồn nước, côn trùng và các dụng cụ trồng trọt. Để phòng trừ các bệnh thối rễ do nấm bệnh gây nên, người nông dân thường sử dụng thuốc hóa học với liều lượng cao. Điều này một mặt sẽ dẫn đến việc kháng thuốc ở các loài VSV gây bệnh, mặt khác sẽ làm ô nhiễm môi trường, làm mất cân bằng sinh thái, ảnh hưởng nghiêm trọng đến sức khỏe con người và các động vật khác. Do an toàn cho con người và cho môi trường, nên biện pháp sử dụng các tác nhân sinh học thay thế các tác nhân hóa học được xem là một chiến lược của Tổ chức Lương thực và Nông nghiệp Liên Hiệp Quốc FAO (FAO, 1992). Một trong số đó là sử dụng các VSV có khả năng đối kháng với các VSV gây bệnh trên cây trồng. Hiện nay, xạ khuẩn là nhóm VSV được quan tâm nghiên cứu nhiều nhất vì chúng có khả năng tiết ra các hoạt chất đối kháng và đặc biệt là các chất kháng mạnh với nhiều loại nấm gây bệnh trên thực vật $(\mathrm{Le}, \mathrm{Dinh}, \mathrm{Vu}, \mathrm{\&}$ Nguyen, 2014). Từ những lí do trên, chúng tôi đã tiến hành nghiên cứu: "Phân lập và tuyển chọn các chủng xạ khuẩn tại tỉnh Lâm Đồng có hoạt tính kháng nấm Pythium vexans gây bệnh thối rễ trên rau ăn lá họ thập tự".

\section{Vật liệu và phương pháp nghiên cứu}

\subsection{Phân lập và kiểm tra khả năng gây bệnh thối rễ của nấm Pythium sp. trên rau ăn}

\section{lá họ thập tụ}

\subsubsection{Phương pháp phân lập nấm bệnh}

Theo Akter, Hossain, Nahar, Meah, và Hossain (2007), quy trình phân lập nấm Pythium sp. gây bệnh thối rễ trên rau ăn lá họ thập tự được thực hiện như sau: Cân $10 \mathrm{~g}$ mẫu rau bị bệnh được cắt thành từng mảnh nhỏ cho vào hộp nhựa, che một miếng vải trắng lên phía trên mẫu. Đổ nước cất vô trùng vào hộp nhựa sao cho mực nước cao hơn so với miếng vải khoảng $01-02 \mathrm{~cm}$. Sau đó, đặt 05 cánh hoa hồng vào hộp, giữ trong điều kiện tối, ở nhiệt độ phòng. Sau 02-03 ngày, 
chọn các cánh hoa hồng bị chuyển màu, khử trùng bề mặt cánh hoa với cồn 70 độ, sau đó cắt thành từng miếng nhỏ có kích thước $05 \times 05 \mathrm{~mm}$, rồi đặt lên bề mặt đĩa môi trường Potato Carrot Agar (PCA) có bổ sung kháng sinh (Chloramphenicol, nồng độ $0.1 \mathrm{~g} / \mathrm{l})$, ủ ở nhiệt độ phòng. Khi thấy có sợi nấm phát triển từ mẫu cánh hoa thì tiến hành cấy truyền và làm thuần (Akter et al., 2007).

\subsubsection{Kiểm tra khả năng gây bệnh của chủng nấm theo quy tắc Koch}

Chuẩn bị dịch huyền phù du động bào tử nấm: Nấm Pythium sp. được nuôi cấy trên môi trường $\mathrm{PCA}$ ở nhiệt độ $25^{\circ} \mathrm{C}$ trong 05 ngày, cắt sinh khối nấm thành từng mảnh nhỏ rồi chuyển vào các bình Erlen chứa $100 \mathrm{ml}$ nước cất vô trùng, để tĩnh ở nhiệt độ phòng trong 02 ngày. Sau đó, đặt các bình Erlen vào tủ mát $\left(4^{\circ} \mathrm{C}\right)$ trong 45 phút. Sau đó, các bình Erlen sẽ được lọc qua bốn lớp vải để thu được huyền phù du động bào tử. Pha loãng huyền phù du động bào tử đến mật độ $10^{4}$ động bào tử/ml. Phương pháp này được thực hiện dựa theo phương pháp của Mohammad và cộng sự (2015) và Shouan và cộng sự (2010) có cải tiến.

Cách thực hiện: thử nghiệm kiểm tra được thực hiện theo phương pháp của Shouan và cộng sự (2010) có cải tiến trên rau cải ngọt. Đầu tiên, các bộ rễ rau cải ngọt (bao gồm cả phần cổ rễ) được rửa sạch dưới vòi nước chảy, khử trùng bộ rễ với dung dịch javel $10 \%$, rửa sạch lại bằng nước vô trùng và làm khô trên giấy thấm vô trùng. Sau đó, đặt các bộ rễ ngập trong dịch huyền phù có chứa mật độ $10^{4} \mathrm{du}$ động bào tử/ml, để yên trong một giờ ở điều kiện phòng. Sau đó, lấy bộ rễ ra và đặt trong các hộp nhựa chứa giấy ẩm được vô trùng, giữ trong điều kiện tối, ủ ở $25^{\circ} \mathrm{C}$ trong 04 ngày. Quan sát biểu hiện của rễ và đánh giá khả năng gây bệnh của chủng nấm Pythium sp. phân lập được.

\subsection{3. Định danh nấm bệnh phân lập được bằng sinh học phân tử}

Sau khi chọn được chủng nấm nghi ngờ là Pythium sp. có khả năng gây bệnh thối rê̂ trên rau họ thập tự, tiến hành tách DNA và khuếch đại vùng gen $C O I$ bằng phản ứng $\mathrm{PCR}$ với cặp mồi chuyên biệt OomCoxI-Levup (5'-AAAAGAGAAGGTGTTTTTTATGGA-3') và OomCoxI-levlo (5'-GCAAAAGCACTAAAAATTAAATATAA-3'). Kiểm tra kết quả điện di của sản phẩm sau PCR trên gel agarose $1 \%$ với thang DNA $01 \mathrm{~kb}$, theo nhóm nghiên cứu của Gregg và cộng sự (2011) thì kích thước đoạn DNA mong muốn phải đạt khoảng 680bp. Sau đó, tiến hành tinh sạch sản phẩm sau $\mathrm{PCR}$ và giải trình tự vùng gen $C O I$ để định danh nấm bệnh thông qua so sánh sự tương đồng với các trình tự khác trên ngân hàng gen vi sinh vật (NCBI).

\subsection{Phưong pháp thu thập và sàng lọc các mẫu đất trồng rau tại Lâm Đồng có tiềm năng đối kháng nấm Pythium vexans}

\subsubsection{Phương pháp thu mẫu}

Mẫu dùng để phân lập xạ khuẩn được thu thập từ 15 vườn trồng rau họ thập tự ở tỉnh Lâm Đồng. Mẫu được lấy theo mô tả của nhóm nghiên cứu của Amin, Ashraf, và Khosrow (2014). Đối với mỗi vườn, thu mẫu ở năm điểm khác nhau (bốn điểm xung quanh vườn và một điểm chính giữa vườn), Mẫu đất sẽ được lấy phía dưới vùng xung quanh rễ của cây rau không bị bệnh với các độ sâu khác nhau từ $05-10 \mathrm{~cm}$, rồi trộn lại thành một mẫu, cho vào bao zipper có dán nhãn. Bảo quản ở $4^{\circ} \mathrm{C}$ cho tới khi làm thí nghiệm.

Ký hiệu: XYi, trong đó: XY là chữ cái đầu của vùng được thu mẫu, i là số thứ tự vườn được thu mẫu.

2.2.2. Phương pháp sàng lọc nhanh các mẫu đất chưa các chủng xạ khuẩn có khả năng đối kháng nấm Pythium vexans 
Cách thực hiện: Nuôi cấy nấm Pythium vexans trên đĩa Petri chứa môi trường PDA trong 05 ngày. Dùng khoan thạch đường kính $05 \mathrm{~mm}$ ấn nhẹ lên bề mặt tản nấm rồi đặt mẫu cấy sang đĩa Petri chứa môi trường PDA ở tâm đĩa. Sau đó dùng khoan đục thạch đường kính $05 \mathrm{~mm}$ đục ba giếng xung quanh khoan nấm Pythium vexans và cách tản nấm $03 \mathrm{~cm}$. Pha loãng $10 \mathrm{~g}$ mẫu đất với $90 \mathrm{ml}$ nước muối sinh lý vô trùng, lắc 200 vòng/phút trong 30 phút, hút $10 \mu 1$ dịch vào mỗi giếng khoan. Đồng nuôi cấy dịch đất với nấm bệnh, theo dõi tốc độ lan tơ của tản nấm sau $24 \mathrm{~h}$, $48 \mathrm{~h}$ và $72 \mathrm{~h}$. Mỗi mẫu đất được lặp lại ba lần, đối chứng là đĩa Petri có chứa nấm bệnh, dịch đất được thay thế bằng nước cất vô trùng. Lựa chọn những mẫu đất có khả năng đối kháng nấm Pythium vexans để tiến hành phân lập xạ khuẩn.

\subsection{Phân lập xạ khuẩn và chuẩn bị mẫu nấm Pythium vexans gây bệnh thối rễ trên}

rau

Sau khi đã có được kết quả sàng lọc các mẫu đất có tiềm năng đối kháng nấm bệnh, tiến hành phân lập xạ khuẩn từ các mẫu đất này.

Cách thực hiện: Sử dụng phương pháp pha loãng thập phân để phân lập chủng xạ khuẩn trên các nồng độ $10^{-2}, 10^{-3}, 10^{-4}$. Cụ thể là cân $10 \mathrm{~g}$ mẫu pha trong $90 \mathrm{ml}$ nước cất đã vô trùng để mẫu có nồng độ $10^{-1}$, tiếp đó hút $1 \mathrm{ml}$ mẫu đó trong $09 \mathrm{ml}$ nước cất vô trùng và tiếp tục pha loãng tới các nồng độ tiếp theo. Sau khi các mẫu đã được pha loãng, hút $100 \mu 1$ dịch mẫu ở nồng độ khảo sát trải trên đĩa thạch chứa môi trường Gause I. Nuôi trong tủ ấm $30^{\circ} \mathrm{C}$ sau 07 ngày, quan sát khuẩn lạc và đánh dấu các khuẩn lạc nghi ngờ là Streptomyces spp. để cấy truyền và làm thuần trên môi trường Grause I (Mansour, Mohamedin, Esmaeel, \& Huda, 2008). Ký hiệu chủng theo tên mẫu thu thập được.

Xác định hình thái cơ quan mang bào tử, bào tử và cách sắp xếp của bào tử dưới kính hiển vi huỳnh quang có vật kính $40 \mathrm{X}$ và $100 \mathrm{X}$ theo nghiên cứu của Pridham, Hesseltine, và Benedict (1958). Kết hợp với đặc điểm khuẩn lạc trên môi trường Gause I để xác định hình thái Streptomyces spp.

Nấm Pythium vexans được nuôi cấy trên môi trường PDA ở nhiệt độ $25^{\circ} \mathrm{C}$ trong 05 ngày.

\subsection{Khảo sát khả năng ức chế Pythium vexans của dịch nuôi cấy loại bỏ tế bào của các chủng xạ khuẩn được phân lập tại Lâm Đồng}

Cách thực hiện: Nấm gây bệnh được nuôi trên đĩa Petri chứa môi trường PDA trong 05 ngày. Các chủng xạ khuẩn được nuôi trên môi trường Gause lỏng ở điều kiện lắc 200 vòng/phút, nhiệt độ $30 \pm 1{ }^{\circ} \mathrm{C}$. Sau 05 ngày, tiến hành ly tâm dịch nuôi cấy xạ khuẩn ở 10,000 vòng/phút trong 15 phút. Thu hoạch dịch nổi, loại bỏ tế bào bên dưới ống li tâm. Dịch nổi sau đó được đem lọc qua màng lọc $0.2 \mu \mathrm{m}$ để loại bỏ các tế bào còn sót lại được dịch chiết 1 . Chuẩn bị môi trường $\mathrm{PDA}$, đem hấp tiệt trùng, để nguội xuống $45^{\circ} \mathrm{C}-50^{\circ} \mathrm{C}$ rồi bổ sung $10 \%$ các dịch chiết 1 vào môi trường, lắc đều rồi phân phối ra các đĩa Petri $(10 \mathrm{ml} /$ đĩa). Dùng khoan thạch đường kính $05 \mathrm{~mm}$ ấn nhẹ lên bề mặt nuôi cấy nấm gây bệnh rồi đặt mẫu cấy sang giữa đĩa Petri, ba lần lặp lại cho mỗi loại dịch chiết của các chủng xạ khuẩn, ủ ở nhiệt độ $25 \pm 1^{\circ} \mathrm{C}, 05$ ngày. Đối chứng: cấy nấm vào giữa đĩa Petri chứa môi trường PDA không bổ sung dịch chiết (Harpreet \& Leena, 2010; Simi, Sajjalaguddam, Vijay, Rajeev, \& Hari, 2015).

Chỉ tiêu theo dõi: đường kính khuẩn lạc nấm bệnh sau $24 \mathrm{~h}, 48 \mathrm{~h}$ và $72 \mathrm{~h}$ ủ. Sàng lọc các chủng xạ khuẩn dựa vào: $\mathrm{H}=(\mathrm{D} 1-\mathrm{D} 2) / \mathrm{D} 1$ x 100

$\mathrm{H}$ : Phần trăm ức chế nấm bệnh trên đĩa Petri (\%);

$\mathrm{D} 1$ : Đường kính khuẩn lạc nấm bệnh trong công thức đối chứng $(\mathrm{mm})$; 
D2: Đường kính khuẩn lạc nấm bệnh khi được nuôi cùng với xạ khuẩn (mm).

\section{5. Định danh sinh học phân tử chủng xạ khuẩn có khả năng đối kháng mạnh nhất nấm Pythium vexans}

Chọn lọc chủng Streptomyces sp. có khả năng đối kháng mạnh nhất nấm Pythium vexans. Xạ khuẩn sẽ được nuôi cấy trên môi trường Gause $\mathrm{I}$ ở $30^{\circ} \mathrm{C}$. Sau 05 ngày, thu hoạch sinh khối xạ khuẩn để tách chiết DNA tổng số.

Thu hoạch DNA tổng số để thực hiện phản ứng PCR. Cặp mồi được sử dụng để khuếch đại đoạn gen 16S-rRNA của các chủng xạ khuẩn trong nghiên cứu là: 20F (AGAGTTTGATCATGGCTCAG) và 1500R (GGTTACCTTGTTACGACTT) theo Kawuri và Darmayasa (2019).

Sản phẩm PCR được điện di trên gel agarose $0.8 \%$ với thang DNA $1 \mathrm{~kb}$ (Nhà sản xuất Fermentas, Đức) để kiểm tra kết quả. Sau đó, tinh sạch sản phẩm PCR bằng kit Isolate II PCR. Chu trình phản ứng thiết lập: 01 chu kỳ ở $95^{\circ} \mathrm{C}-04$ phút; 30 chu kỳ gồm có: $94^{\circ} \mathrm{C}-01$ phút, $54^{\circ} \mathrm{C}-45$ giây và $72^{\circ} \mathrm{C}-01$ phút 45 giây; 01 chu kỳ ở $72^{\circ} \mathrm{C}-10$ phút; tổng thể tích phản ứng là $25 \mu 1$. Sản phẩm sau khi tinh sạch được giải trình tự. Kết quả thu được sẽ xử lý bằng phần mềm ATGC, BLAST trình tự đã xử lý lên NCBI để so sánh sự tương đồng với trình tự các chủng đã có sẵn. Xây dựng cây phát sinh loài bằng phần mềm MEGA7.

\section{Kết quả và thảo luận}

\subsection{Kết quả phân lập và kiểm tra khả năng gây bệnh thối rễ của nấm Pythium sp. trên rau ăn lá họ thập tụ̂}

Từ ba mẫu rau ăn lá họ thập tự có triệu chứng bệnh thối rễ do nấm Pythium sp. gây ra tại vườn rau ở Lâm Đồng. Sau 02 ngày quan sát bẫy nấm bằng cánh hoa hồng, cho thấy có hai mẫu rau làm chuyển màu cánh hoa như ở Bảng 1 . Kết quả phân lập nấm Pythium sp. từ những cánh hoa đã chuyển màu này trên môi trường PCA có bổ sung kháng sinh thu được hai chủng nấm ký hiệu RR1 và RR2 có đặc điểm hình thái đại thể và vi thể như Bảng 1 . Sau 05 ngày nuôi cấy trên môi trường $\mathrm{PCA}$, các tản nấm này đều có hình dáng đặc trưng của nấm Pythium sp. như hình cánh hoa hồng, ngôi sao, ... Bên cạnh đó, kết quả quan sát hình thái vi thể dưới kính hiển vi cũng cho thấy, cả 2 chủng RR1 và RR2 đều có túi bào tử hình tròn và chứa nhủ trong suốt (Bảng 1), giống với mô tả của Hon (2018) về các loài nấm trong Pythium sp. trong họ Pythiaceae.

Từ các kết quả trên, tiến hành đánh giá khả năng gây bệnh nhân tạo của cả hai chủng phân lập này trên bộ rễ rau cải ngọt. Sau 04 ngày thử nghiệm chủng bệnh nhân tạo theo quy tắc Koch, kết quả cho thấy bộ rễ ở chủng RR1 đã biểu hiện những dấu hiệu của bệnh thối rễ, đặc biệt là các rễ tơ gần như đã bị thối đen hết toàn bộ. Còn bộ rễ ở chủng RR2 vẫn chưa biểu hiện rõ triệu chứng bệnh. Kết quả này phù hợp với nghiên cứu trước đó của nhóm nghiên cứu của Lester, Burgess, Knight, và Phan (2009). Trong khi đó, bộ rễ ở nghiệm thức đối chứng vẫn không biểu hiện bệnh, các rễ tơ hầu như không bị thối đen (Hình 1). Sau đó, tiến hành tái phân lập lại nấm từ bộ rễ ở nghiệm thức RR1. Kết quả cho thấy chủng nấm tái phân lập này có hình thái giống với hình thái của chủng ban đầu. Từ những kết quả này cho thấy, chủng nấm RR1 có tiềm năng gây bệnh thối rễ trên rau họ thập tự. 

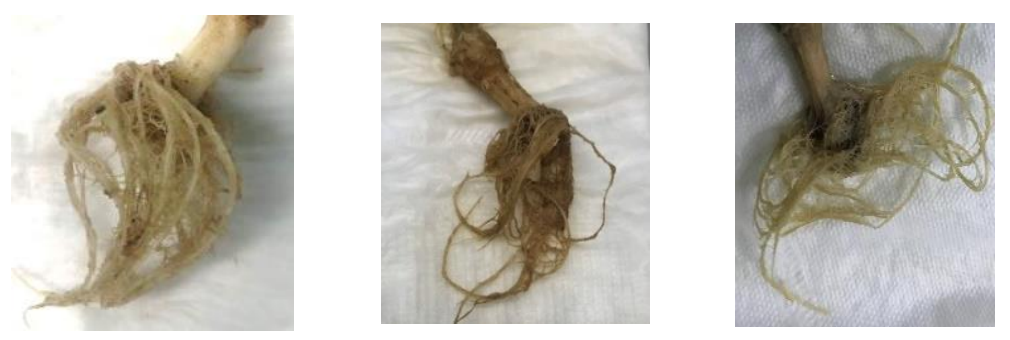

\section{Đối chứng}

\section{RR1}

RR2

Hình 1. Kết quả chủng bệnh nhân tạo theo quy tắc Koch trên rễ rau cải của chủng RR1 và RR2 sau 04 ngày

\section{Bảng 1}

Kết quả bẫy cánh hoa hồng và hình ảnh đại thể, vi thể của các chủng nấm RR1 và RR2

\begin{tabular}{|c|c|c|}
\hline Tên chủng & RR1 & RR2 \\
\hline $\begin{array}{c}\text { Cánh hoa hồng bị mất } \\
\text { màu }\end{array}$ & & \\
\hline Đại thể & & \\
\hline & & \\
\hline
\end{tabular}

Nguồn: Kết quả phân tích dữ liệu của nhóm nghiên cứu

Sau đó, tiến hành tách chiết DNA của chủng RR1, khuếch đại vùng trình tự gen $C O I$ của chủng nấm RR1 bằng phản ứng Polymerase Chain Reaction (PCR) với cặp mồi đặc hiệu là OomLevup (5'-AAAAGAGAAGGTGTTTTTTATGGA-3') và Oomlevlo (5' GCAAAAGCACTAAAAATTAAATATAA-3'). Kết quả điện di ở Hình 2 cho thấy, đoạn trình tự được khuếch đại có kích thước khoảng 680bp phù hợp với kết quả của Gregg và cộng sự (2011). Tiến hành tinh sạch và giải trình tự sản phẩm PCR thu được, xử lý trình tự bằng phần mềm ATGC và BLAST so sánh với trình tự gen của các chủng thuộc ngân hàng gen NCBI. Kết quả so sánh cho thấy, chủng RR1 có độ tương đồng 99.14\% với chủng Pythium vexans STEU6712 được trình bày ở Bảng 2. 


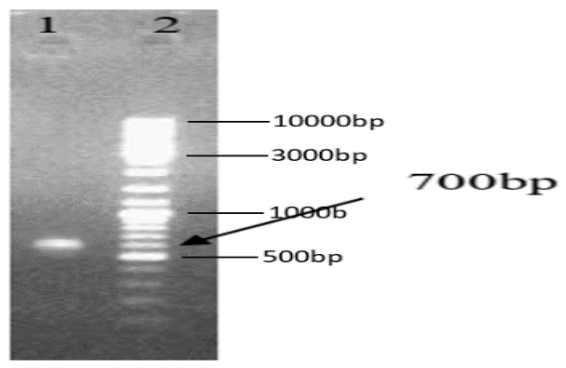

1. Sản phẩm sau PCR của chủng RR1

2. Thang DNA

Hình 2. Kết quả điện di DNA của chủng nấm RR1 gây bệnh thối rễ rau cải

\section{Bảng 2}

Kết quả BLAST vùng gen $C O I$ của chủng RR1

\begin{tabular}{cccccc}
\hline Tên chủng & $\begin{array}{c}\text { Mã số chủng so } \\
\text { sánh }\end{array}$ & $\begin{array}{c}\text { Độ tương đồng } \\
(\%)\end{array}$ & Độ phủ & Tên loài \\
\hline RR1 & GU133471.1 & 99.14 & 99 & Pythium vexans \\
\hline
\end{tabular}

Nguồn: Kết quả xử lý từ dữ liệu điều tra

Trình tự gen $C O I$ của chủng RR1 được khuếch đại bằng cặp mồi OomCoxI-Levup và OomCoxI-levlo:

CTTTTTTCAACAAATCATAAAGATATTGGTACTTTATATTTAATTTTTGGTGCT TTTTCAGCAATAGTTGCAACTGTAATGTCTGTATTAATTAGAATTGAATTAGCACAA CCAGGTAATCAAATTTTTATGGGAAACCATCAAGTATATAATGTTATGATTACAGCA CACGGTTTATTAATGATATTTTTTGTGGTTATGCCTATATTAGTTGGTGGTTTTGGTA ACTGGTTTGTACCTATAATGGTAGGAGCACCTGATATGGCTTTTCCTCGTTTAAATA ATATTAGTTTTTGGTTATTACCACCATCTTTATTACTATTAGTATCTTCTGCTTTAGTT GAATCAGGTGCAGGTACCGGTTGGACAGCTTATCCACCATTATCAAGTGTAGCTGCA CATTCAGGACCTTCAATAGATTTAGCTATTTTTAGTTTACATTTATCAGGTATTTCTT CATTATTAGGTGCAATTAATTTTATTGTTACTATTTTTAATATGAGAGCTCCTGGATT AAGTATGCATAGAATGCCTTTATTTGTATGGTCTCTTTTAATTACAGCTTTTCTTTTA GTTATAACTTTACCAGTATTTTCAGGTTCAATAACTATGTTATTAACTGATAGAAATT TTAATACTTCTTTTTATGACCCAGCAGGAGGAGGAGATCCAGTATTATTCCAACATT TATTTTGGTTTTTCG

3.2. Kết quả thu thập và sàng lọc các mẫu đất trồng rau tại Lâm Đồng có tiềm năng đối kháng nấm Pythium vexans

Từ 15 mẫu đất thu thập được tại các vườn trồng rau họ thập tự ở Lâm Đồng. Sau khi sàng lọc thì 10/15 mẫu đất thu thập được có dấu hiệu đối kháng với Pythium vexans, được ký hiệu từ LD1 đến LD15 (Hình 3). 


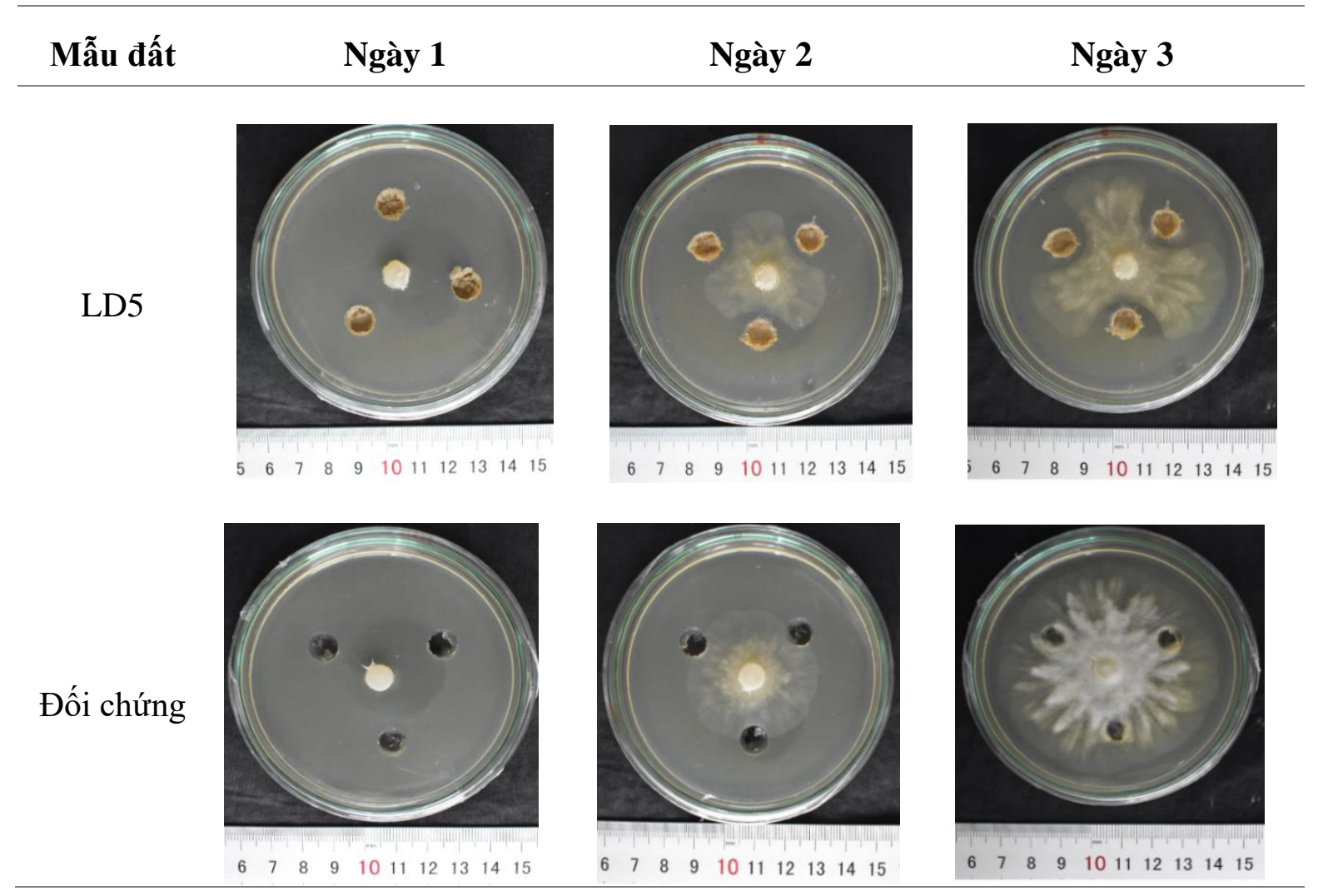

Hình 3. Kết quả sàng lọc mẫu đất LD5 và đối chứng trên môi trường thạch PDA

Từ kết quả Hình 1 , cho thấy trong 10/15 mẫu đất xuất hiện dấu hiệu đối kháng với Pythium vexans, mẫu đất LD5 là có dấu hiệu đối kháng nấm bệnh tốt nhất so với các mẫu đất còn lại. Điều này chứng tỏ, mẫu đất LD5 có tiềm năng chứa hệ vi sinh vật có khăng đối kháng tốt với nấm gây bệnh thối rễ trên rau họ thập tự như Streptomyces spp., Bacillus spp.,...

\subsection{Phân lập xạ khuẩn và chuẩn bị mẫu nấm Pythium vexans gây bệnh thối rễ trên rau}

Từ các mẫu đất này, 20 chủng xạ khuẩn đã được phân lập trên môi trường Gause I với các đặc điểm màu sắc và khuẩn lạc khác nhau. Hình dạng khuẩn lạc, bào tử và hệ sợi khí sinh dựa trên bảng màu chi Streptomyces của tác giả Tresner và Backus (1963). Trong số 20 chủng Streptomyces sp. phân lập được có năm nhóm màu xuất hiện với số lượng và tỷ lệ khác nhau (Hình 4 và Bảng 3 ).

\section{Bảng 3}

Sự phân bố theo nhóm màu của các chủng xạ khuẩn

\begin{tabular}{cccc}
\hline STT & Nhóm màu & Số chủng & Tỷ lệ $\mathbf{\%})$ \\
\hline 1 & Trắng & 11 & 55 \\
\hline 2 & Đen & 1 & 5 \\
\hline 3 & Nâu đất & 4 & 20 \\
\hline 4 & Xám & 3 & 15 \\
\hline 5 & Xanh & 1 & 5 \\
\hline
\end{tabular}

Nguồn: Kết quả phân tích dữ liệu của nhóm nghiên cứu 


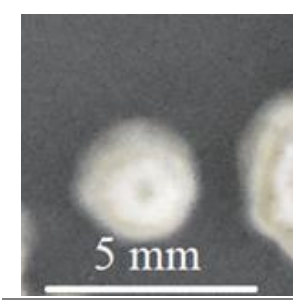

Khuẩn lạc màu trắng

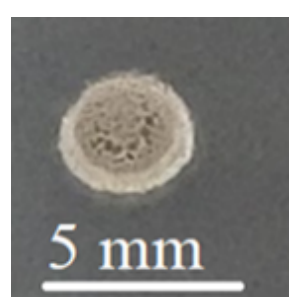

Khuẩn lạc màu đen

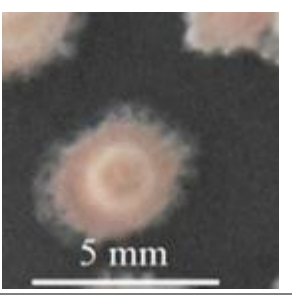

Khuẩn lạc màu nâu đất

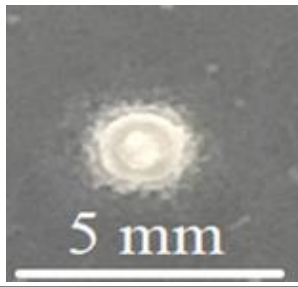

Khuẩn lạc màu xám

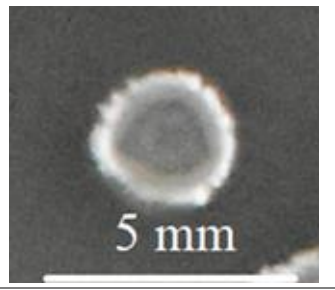

Khuẩn lạc màu xanh

Hình 4. Hình ảnh màu sắc khuẩn lạc đại diện cho năm nhóm màu xạ khuẩn phân lập được tại các vườn rau ở lâm đồng trên môi trường Gause I sau khi sàng lọc

3.4. Kết quả khảo sát khả năng ức chế Pythium vexans của dịch nuôi cấy loại bỏ tế bào của các chủng xạ khuẩn đự̛̣c phân lập tại Lâm Đồng

Khả năng ức chế tố độ lan tơ nấm Pythium vexans của dịch nuôi cấy loại bỏ tế bào của các chủng Streptomyces spp. sau 48 giờ. Kết quả thể hiện ở Bảng 4 và Hình 5 .

\section{Bảng 4}

Hiệu quả ức chế tố độ lan tơ của chủng nấm Pythium vexans của các chủng Streptomyces spp. phân lập ở tỉnh Lâm Đồng sau 48 giờ

Phần trăm ức chế tốc độ lan tơ nấm (\%)

\begin{tabular}{ccc} 
STT & Tên chủng & Sau 48 giò̀ \\
\hline $\mathbf{1}$ & LD1.1 & $14.29^{\mathrm{cd}}$ \\
\hline $\mathbf{2}$ & LD1.2 & $23.12^{\mathrm{c}}$ \\
\hline $\mathbf{4}$ & LD2.1 & $13.20^{\mathrm{cd}}$ \\
\hline $\mathbf{5}$ & LD2.2 & $0.00^{\mathrm{e}}$ \\
\hline $\mathbf{6}$ & LD3.1 & $14.30^{\mathrm{cd}}$ \\
\hline $\mathbf{7}$ & LD3.2 & $0.00^{\mathrm{e}}$ \\
\hline $\mathbf{8}$ & LD4.1 & $18.07^{\mathrm{cd}}$ \\
\hline $\mathbf{9}$ & LD5.2 & $12.95^{\mathrm{cd}}$ \\
\hline $\mathbf{1 0}$ & LD5.4 & $51.80^{\mathrm{a}}$ \\
\hline $\mathbf{1 1}$ & LD6.1 & $8.53^{\mathrm{de}}$ \\
\hline $\mathbf{1 2}$ & LD6.4 & $39.60^{\mathrm{b}}$ \\
\hline $\mathbf{1 3}$ & LD7.1 & $24.90^{\mathrm{c}}$ \\
\hline $\mathbf{1 4}$ & LD7.2 & $13.79^{\mathrm{cd}}$ \\
\hline $\mathbf{1 5}$ & LD8.1 & $14.46^{\mathrm{cd}}$ \\
\hline $\mathbf{1 6}$ & LD8.2 & $20.72^{\mathrm{cd}}$ \\
\hline $\mathbf{1 7}$ & LD9.1 & $17.73^{\mathrm{cd}}$ \\
\hline & LD9.2 & $17.97^{\mathrm{cd}}$ \\
\hline
\end{tabular}




\begin{tabular}{ccc}
\hline STT & Tên chủng & Sau 48 giò̀ \\
\hline $\mathbf{1 8}$ & LD10.1 & $23.79 \mathrm{c}$ \\
\hline $\mathbf{1 9}$ & LD10.2 & $14.30^{\mathrm{cd}}$ \\
\hline $\mathbf{2 0}$ & LD10.3 & $17.56^{\mathrm{cd}}$ \\
\hline & Trung bình & 18.06 \\
\hline & $\mathbf{C V}(\boldsymbol{\%})$ & 36.98 \\
\hline & $\mathbf{P}$ & $<.0001$ \\
\hline
\end{tabular}

Nguồn: Kết quả phân tích dữ liệu của nhóm nghiên cứu

Trong cùng một cột, các giá trị trung bình có kí tự theo sau giống nhau không có sự khác biệt về mặt thống kê $(\mathrm{P}<0.05)$.

Dựa vào kết quả đối kháng ở Bảng 4 cho thấy, Phần trăm ức chế sự lan tơ nấm của 20 chủng Streptomyces sp. có sự khác nhau giữa các chủng (sự khác biệt giữa các nghiệm thức có ý nghĩa về mặt thống kê). Sau 48 giờ nuôi cấy có 18/20 dịch nuôi cấy loại bỏ tế bào của các chủng xạ khuẩn Streptomyces spp. biểu hiện khả năng ức chế sự lan tơ của nấm bệnh chiếm $90 \%$. Khuẩn lạc nấm bị ức chế sẽ có đường kính nhỏ hơn so với khuẩn lạc ở nghiệm thức đối chứng (Hình 5). Trong đó, phần trăm ức chế tơ nấm đạt từ $8.53 \%$ đến $51.8 \%$. Trong đó, chủng xạ khuẩn LD5.4 có hiệu quả ức chế nấm bệnh sau 48 giờ đạt $51.8 \%$. Thấp nhất là chủng LD2.2 $(0 \%)$ và LD3.2 $(0 \%)$ (Hình 5). Phần trăm ức chế nấm giữa các chủng đều có sự khác biệt có ý nghĩa về mặt thống kê sau 48 giờ nuôi cấy. Kết quả này cao hơn nhóm nghiên cứu của Le và cộng sự (2014) khi khảo sát chủng xạ khuẩn NA1 và HN6 đối kháng với nấm gây hại thực vật. Bên canh đó, nghiên cứu của Trinh (2014) cũng cho thấy khả năng sinh chất kháng nấm Pythium sp. của các chủng xạ khuẩn được phân lập. Từ những kết quả trên cho thấy chủng Streptomyces sp. LD 5.4 có khả năng kiểm soát tốt đối với sự phát triển nấm Pythium vexans gây bệnh thối rễ trên rau.

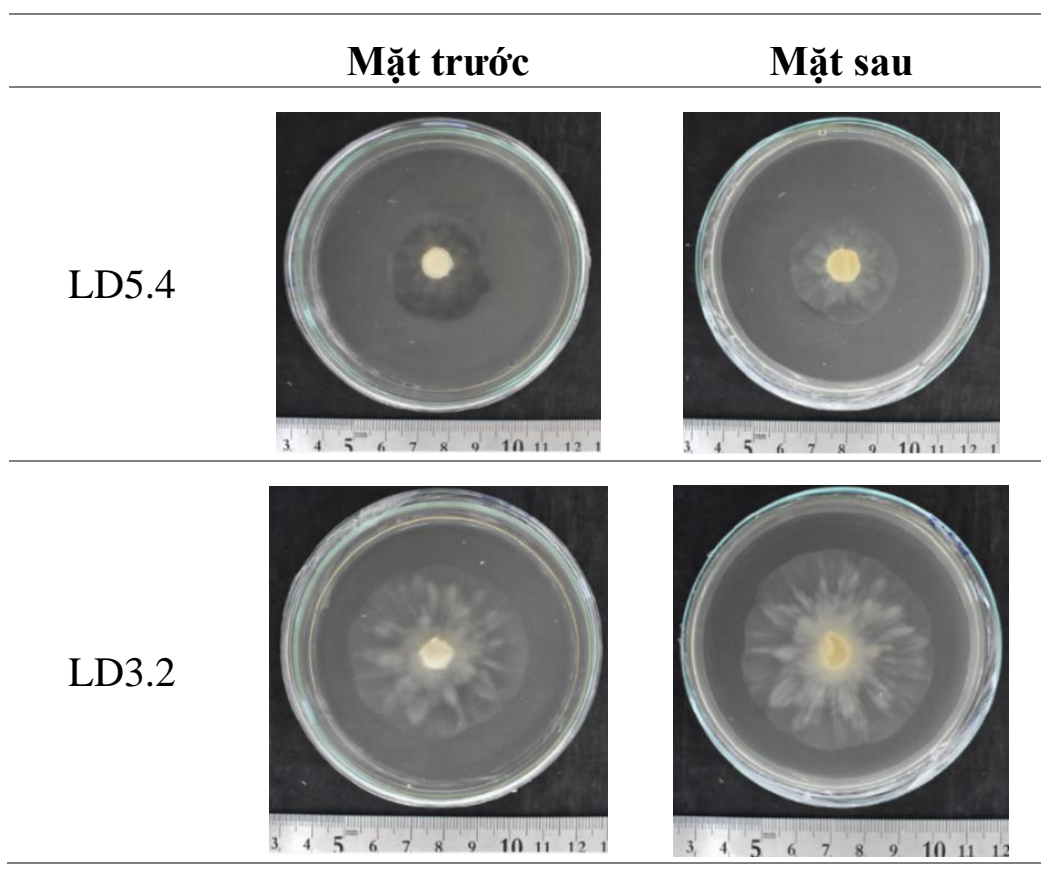




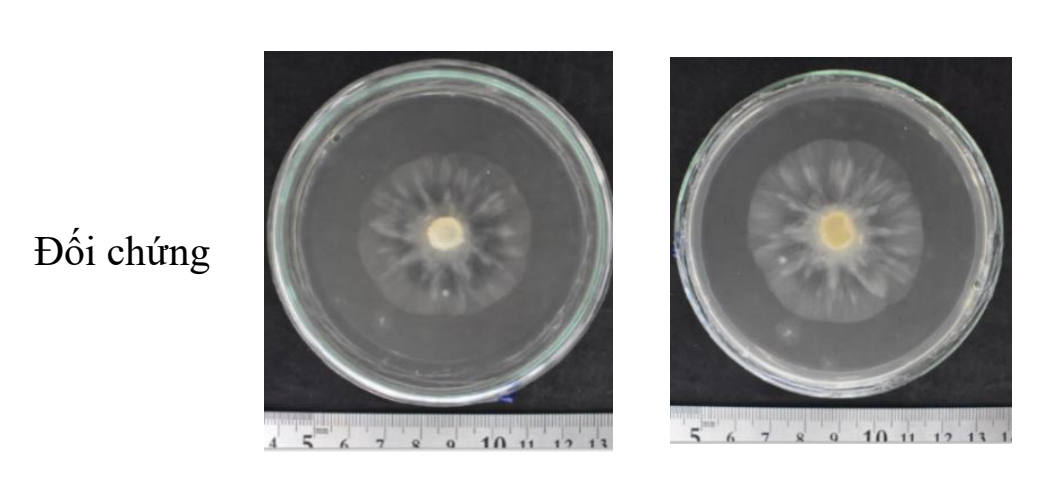

Hình 5. Khuẩn lạc nấm Pythium vexans ở nghiệm thức đối chứng và nghiệm thức nuôi cùng dịch chiết từ chủng LD5.4 và LD3.2 sau 48 giờ

\section{5. Định danh sinh học phân tủ̉ chủng xạ khuẩn LD5.4 có khả năng đối kháng mạnh nhất nấm Pythium vexans}

Từ kết quả sàng lọc trên, lựa chọn được chủng Streptomyces LD5.4 là chủng có tiềm năng kiểm soát nấm Pythium vexans gây bệnh thối rễ trên rau nhờ tiết hoạt chất thứ cấp. Tiến hành tách DNA tổng số các chủng LD5.4 và thực hiện phản ứng PCR với cặp mồi 20F, 1500R. Kết quả điện di sản phẩm PCR cho thấy, chủng LD5.4 xuất hiện vạch có kích thước khoảng $1,300 \mathrm{bp}$, phù hợp với kết quả nghiên cứu của Kawuri và Darmayasa (2019) (Hình 6). Sản phẩm $\mathrm{PCR}$ sau đó được tinh sạch bằng bộ Isolate II $\mathrm{PCR}$ và Gel Kit (Bioline) và tiến hành giải trình tự. Sau khi đọc trình tự bằng phần mềm $\mathrm{ATGC}$ và $\mathrm{BLAST}$ so sánh với ngân hàng gen NCBI. Kết quả so sánh cho thấy, chủng LD5.4 có độ tương đồng $100 \%$ với trình tự gen của chủng Streptomyces filamentosus AY999878.1 về trình tự vùng 16S-rRNA cụ thể như ở Bảng 5.

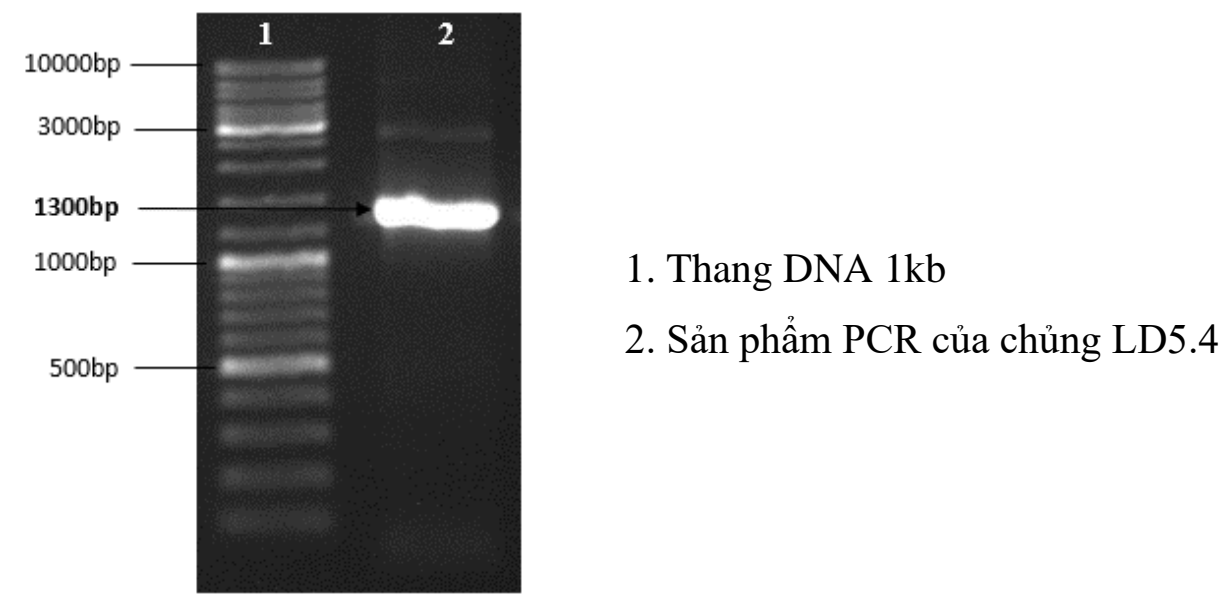

Hình 6. Kết quả điện di DNA của chủng Streptomyces LD5.4

Đặc điểm hình thái của chủng LD5.4 được cấy trên môi trường Gause I và nuôi cấy trong 07 ngày ở $30^{\circ} \mathrm{C}$ tạo khuẩn lạc có dạng tròn, bề mặt hơi xù xì. Màu khuẩn lạc thay đồi theo thời gian nuôi cấy, ở 01-05 ngày đầu nuôi cấy khuẩn lạc có màu trắng, hình tròn, kích thước 01$02 \mathrm{~mm}$, bề mặt mịn và lồi lên. Từ ngày 05 trở đi khuẩn lạc bắt đầu chuyển dần sang màu nâu nhạt hay nâu đỏ với đường kính khoảng 02-03mm, phía xung quanh khuẩn lạc có những tơ mọc mọc ra xung quanh. Mặt dưới khuẩn lạc phẳng, khuẩn ty cơ chất có màu trắng hồng. Khi quan sát hình thái hệ sợ và bào tử của chủng LD5.4 bằng kính hiển vi quang học có độ phóng đại 1,000 lần, kết quả cho thấy sau 05 ngày bắt đầu hình thành bào tử. Chuỗi bào tử dạng chuối thẳng, chuỗi bào tử dài 06-09 bào tử ở mõi chuỗi có đặc điểm giống với chi Streptomyces phù hợp với khóa phân loại của nhóm nghiên cứu Pridham và cộng sự (1958) (Hình 7). 


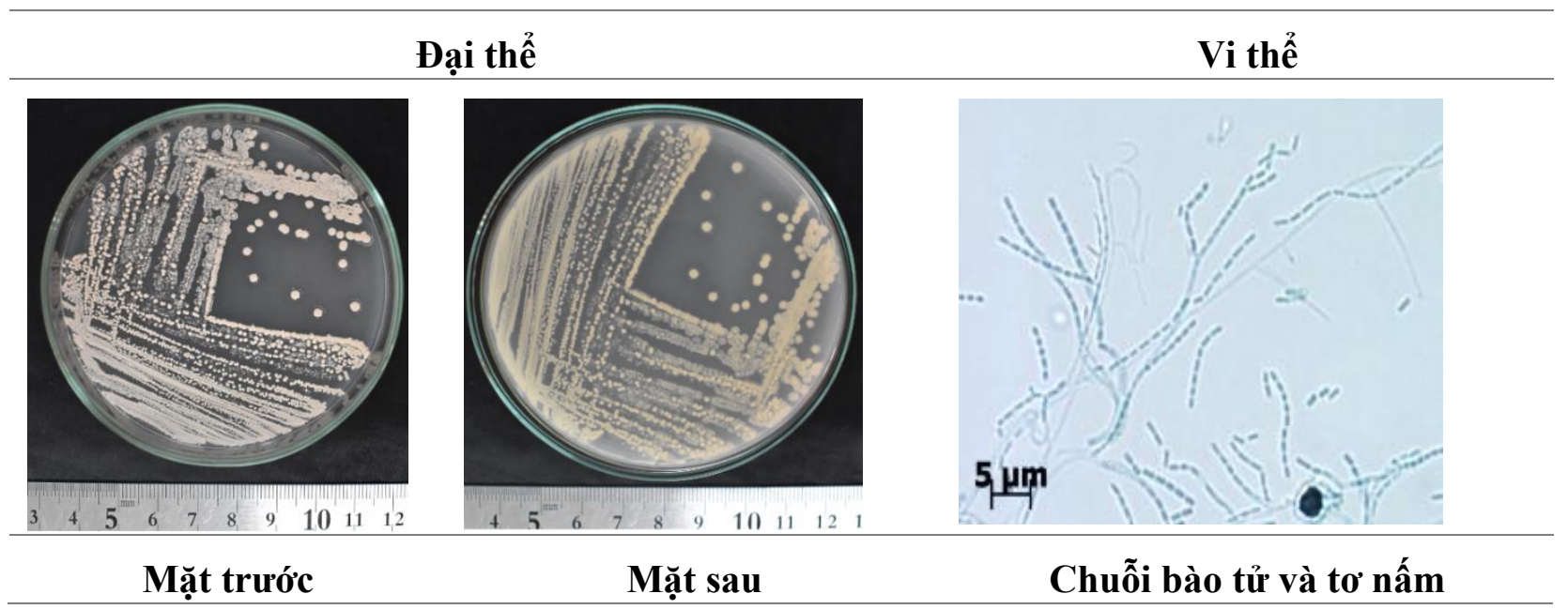

Hình 7. Đặc điểm hình thái khuẩn lạc và vi thể của chủng LD5.4 nuôi trên môi trường Gause I

\section{Bảng 5}

Kết quả BLAST vùng gen 16S rRNA của chủng LD5.4

\begin{tabular}{cccccc}
\hline Tên chủng & $\begin{array}{c}\text { Mã số chủng so } \\
\text { sánh }\end{array}$ & $\begin{array}{c}\text { Độ tương đồng } \\
(\boldsymbol{\%})\end{array}$ & Độ phủ & Tên loài \\
\hline LD5.4 & FJ792560 & 100 & 99.57 & $\begin{array}{c}\text { Streptomyces } \\
\text { filamentosus }\end{array}$ \\
\hline
\end{tabular}

Nguồn: Kết quả xử lý từ dữ liệu điều tra

Trình tự đoạn DNA được khuếch đại bằng cặp mồi $20 \mathrm{~F}$ và $1500 \mathrm{R}$ cùa chủng LD5.4:

GCTTACCATGCAAGTCGAACGATGAAGCCCTTCGGGGTGGATTAGTGGCGAACGGG TGAGTAACACGTGGGCAATCTGCCCTTCACTCTGGGACAAGCCCTGGAAACGGGGT CTAATACCGGATACGACTTGTCGAGGCATCTTGAGGGGTGGAAAGCTCCGGCGGTG AAGGATGAGCCCGCGGCCTATCAGCTTGTTGGTGGGGTAACGGCCCACCAAGGCGA CGACGGGTAGCCGGCCTGAGAGGGCGACCGGCCACACTGGGACTGAGACACGGCCC AGACTCCTACGGGAGGCAGCAGTGGGGAATATTGCACAATGGGCGAAAGCCTGATG CAGCGACGCCGCGTGAGGGATGACGGCCTTCGGGTTGTAAACCTCTTTCAGCAGGG AAGAAGCGAAAGTGACGGTACCTGCAGAAGAAGCGCCGGCTAACTACGTGCCAGCA GCCGCGGTAATACGTAGGGCGCAAGCGTTGTCCGGAATTATTGGGCGTAAAGAGCT CGTAGGCGGCTTGTCACGTCGGGTGTGAAAGCCCGGGGCTTAACCCCGGGTCTGCAT CCGATACGGGCAGGCTAGAGTGTGGTAGGGGAGATCGGAATTCCTGGTGTAGCGGT GAAATGCGCAGATATCAGGAGGAACACCGGTGGCGAAGGCGGATCTCTGGGCCATT ACTGACGCTGAGGAGCGAAAGCGTGGGGAGCGAACAGGATTAGATACCCTGGTAGT CCACGCCGTAAACGTTGGGAACTAGGTGTTGGCGACATTCCACGTCGTCGGTGCCGC AGCTAACGCATTAAGTTCCCCGCCTGGGGAGTACGGCCGCAAGGCTAAAACTCAAA GGAATTGACGGGGGCCCGCACAAGCAGCGGAGCATGTGGCTTAATTCGACGCAACG CGAAGAACCTTACCAAGGCTTGACATATACCGGAAAGCGCCAGAGATGGTGCCCCC CTTGTGGTCGGTATACAGGTGGTGCATGGCTGTCGTCAGCTCGTGTCGTGAGATGTT GGGTTAAGTCCCGCAACGAGCGCAACCCTTGTCCTGTGTTGCCAGCATGCCCTTCGG GGTGATGGGGACTCACAGGAGACCGCCGGGGTCAACTCGGAGGAAGGTGGGGACG 


\section{ACGTCAAGTCATCATGCCCCTTATGTCTTGGGCTGCACACGTGCTACAATGGCCGGT ACAAAGAGCTGCGATGCCGCGAGGCGGAGCGAATCTCAAAAAGCCGGTCTCAGTTC GGATTGGGGTCTGCAACTCGACCCCATGAAGTCGGAGTTGCTAGTAATCGCAGATCA GCATTGCTGCGGTGAATACGTTCCCGGGCCTTGTACACACCGCCCGTCACGTCACGA AAGTCGGTAACACCCGAAGCCGGTGGTCCCAACCCCTCGGGGAGGGAGC}

Kết quả khi phân tích cây phát sinh loài của chủng xạ khuẩn LD5.4 với các loài tham khảo bằng phần mềm MEGA8, cho thấy chủng LD5.4 gần với xạ khuẩn Streptomyces filamentosus và không có tương đồng với loài gây bệnh (Escherichia coli), tương tự như kết quả BLAST trên NCBI (Bảng 4 và Hình 8).

Từ các kết quả này cho phép kết luận chủng xạ khuẩn LD5.4 là chủng xạ khuẩn Streptomyces filamentosus. Theo Bavya, Mohanapriya, Pazhanimurugan, và Balagurunathan (2011) cũng đã cho thấy nhiều lợi ích và an toàn của chủng Streptomyces filamentosus trong đối kháng vi sinh vật gây hại.

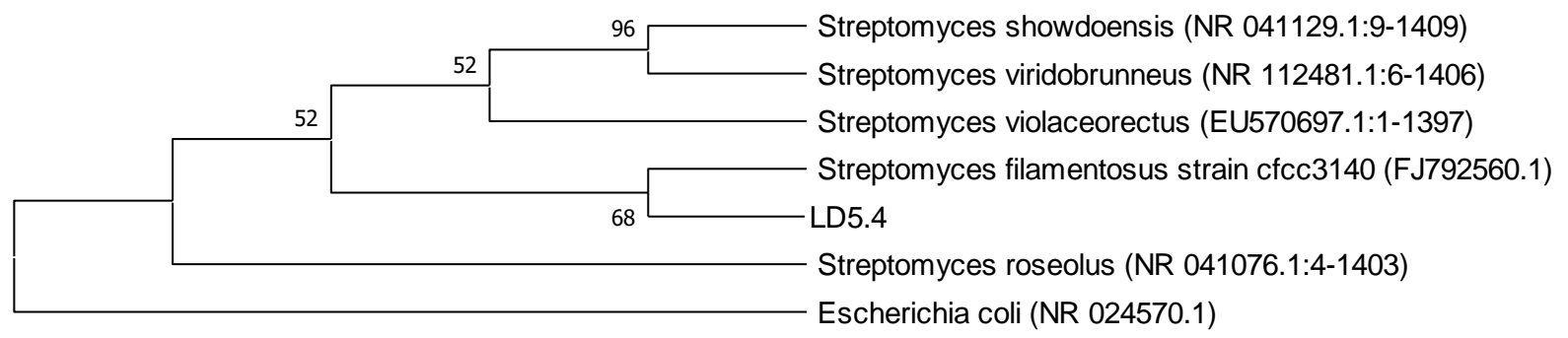

Hình 8. Cây phát sinh loài của chủng xạ khuẩn LD5.4 với các loài xạ khuẩn có quan hệ họ hàng gần dựa trên phân tích trình tự $16 \mathrm{~S}$ rRNA

\section{Kết luận và kiến nghị}

Từ 15 mẫu đất thu được tại các vùng trồng rau họ thập tự tại Lâm đồng, đã phân lập được 20 chủng Streptomyces spp. và 1 chủng nấm Pythium vexans từ mẫu rau bệnh thối rễ trên rau họ thập tự. Kết quả sàng lọc được 1 chủng Streptomyces sp. (LD5.4) có khả năng sinh hoạt chất ức chế nấm Pythium vexans gây bệnh thối rễ trên rau đạt $51.80 \%$ sau 48 giờ bằng dịch môi trường nuôi cấy đã loại bỏ tế bào và cao hơn các chủng Streptomyces sp. còn lại. Kết quả định danh sinh học phân tử cho thấy, chủng LD5.4 tương đồng 100\% với chủng Streptomyces filamentosus FJ792560. Tuy nhiên, hiệu quả ức chế nấm của chủng LD5.4 cần được tiến hành khảo sát thêm một số điều kiện nuôi cấy, thời gian, khả năng ức chế Pythium vexans trong điều kiện in vivo để tăng cao hiệu lực ức chế bệnh thối rễ trên rau.

\section{Tài liệu tham khảo}

Akter, M. K., Hossain, M. D., Nahar, K., Meah, M. B., \& Hossain, M. A. (2007). Isolation and identification of Phytophthora capsici and its mating type determination. Journal of Agroforestry and Environment, 1(2), 89-92.

Amin, H., Ashraf, K., \& Khosrow, I. (2014). Streptomycetes: Characteristics and their antimicrobial activities. International Journal of Advanced Biological and Biomedical Research, 2(1), 63-75.

Bavya, M., Mohanapriya, P., Pazhanimurugan, R., \& Balagurunathan, R. (2011). Potential bioactive compound from marine actinomycetes against biofouling bacteria. Indian of GeoMarine Sciences, 40(4), 578-582. 
Food and Agriculture Organization (FAO). (1992). The state of food and agriculture 1992. Retrieved January 10, 2021, from fao.org/3/t0656e/t0656e.pdf

Gregg, P. R., Arthur, W. A. M. D. C., Michael, D. C., Hermann, V., Henk, B., Kanak, B., . . . Andre, L. V. C. (2011). DNA barcoding of oomycetes with cytochrome c oxidasesubunit I and internal transcribed spacer. Molecular Ecology Resources, 11(6), 1002-1011.

Harpreet, S., \& Leena, P. (2010). Antifungal activity of extracts obtained from actinomycetes. Journal of Yeast and Fungal Research, 1(10), 197-200.

Hon, H. H. (2018). The taxonomy and biology of Phytophthora and pythium. Journal Bacteriol Mycol Open Access, 6(1), 40-45.

Kawuri, R., \& Darmayasa, I. B. G. (2019). Bioactive compound of streptomyces capoamus as biocontrol of bacterial wilt disease on banana plant. IOP Conference Series: Earth and Environmental Science, 347(2019), 1-8. doi:10.1088/1755-1315/347/1/012054

Le, H. T., Dinh, L. V., Vu, V. T., \& Nguyen, G. V. (2014). Phân lập và tuyển chọn các chủng xạ khuẩn (Streptomyces spp.) đối kháng nấm gây bệnh thực vật [Isolation and selection of actinomycete strains (Streptomyces spp.) antagonistic to plant pathogenic fungi nấm]. Tạp chí Khoa học và Phát triển 2014, 12(5), 656-664.

Lester, W., Burgess, T. E., Knight, L. T., \& Phan, H. T. (2009). Cẩm nang chẩn đoán bệnh cây ở Việt Nam [Diagnostic manual for tree diseases in Vietnam]. Canberra, Australia: Trung tâm nghiên cứu nông nghiệp quốc tế Australia (ACIAR).

Mansour, F. A., Mohamedin, A. H., Esmaeel, A. E., \& Huda, H. B. (2008). Control of potato bacterial soft rot disease caused by erwinia carotovora subsp. carotovora with streptomyces sioyaensis and cinnamon oil. Egyptian Journal of Microbiology, 43, 1-20.

Mohammad, Z. R., Seiji, U., Etsuo, K., Takeshi, K., Mikio, K., Keiichi, M., . . Koji, K. (2015). Two plant pathogenic species of Phytophthora associated with stem blight of Easter lily and crown rot of lettuce in Japan. Mycoscience, 56(4), 419-433.

NCBI. (n.d.). Retrieved January 10, 2021, from https://www.ncbi.nlm.nih.gov/gene

Nguyen, D. L., \& Nguyen, K. T. N. (2006). Các nhóm vi khuẩn chủ yếu - Phân loại vi sinh vật [Major groups of bacteria - Classification of microorganisms]. Hanoi, Vietnam: NXB Giáo Dục.

Pridham, T. G., Hesseltine, C. W., \& Benedict, R. G. (1958). A guide for the classification of streptomycetes according to selected groups. Placement of strains in morphological sections. Journal of Applied Microbiology, 6(1), 52-79.

Shouan, Z., Thomas, L. W., Miriam, C. M., John, A. M., Joseph, W. K., \& Waldemar, K. (2010). Evaluation of plant growth-promoting rhizobacteria for control of Phytophthora blight on squash under greenhouse conditions. Biological Control, 53(1), 129-135.

Simi, J., Sajjalaguddam, R. R., Vijay, K. K., Rajeev, V., \& Hari, K. S. (2015). Assessing the prospects of Streptomyces spp. RP1A-12 in managing groundnut stem rot disease caused by Sclerotium rolfsii. Journal of General Plant Pathology, 2(6), 23-31.

Tresner, H. D., \& Buckus, E. J. (1963). System of color wheels for Streptomyces taxonomy. Journal of Applied Microbiology, 11(4), 335-338.

Trinh, A. T. (2014). Phân lập và tuyển chọn xạ khuẩn có khả năng sinh chất kháng nấm Pythium 
sp [Isolation and selection of actinomycetes capable of producing antifungal agents Pythium sp]. Tạp chi khoa hoc Đại học Su phạm Tp.HCM, 61(2014), 113-121.

\section{PHỤ LỤC}

\section{A. Kết quả phổ giải trình tụ chủng RR1}

A.1. Phổ giải trình tụ bằng mồi OomCoxI-Levup

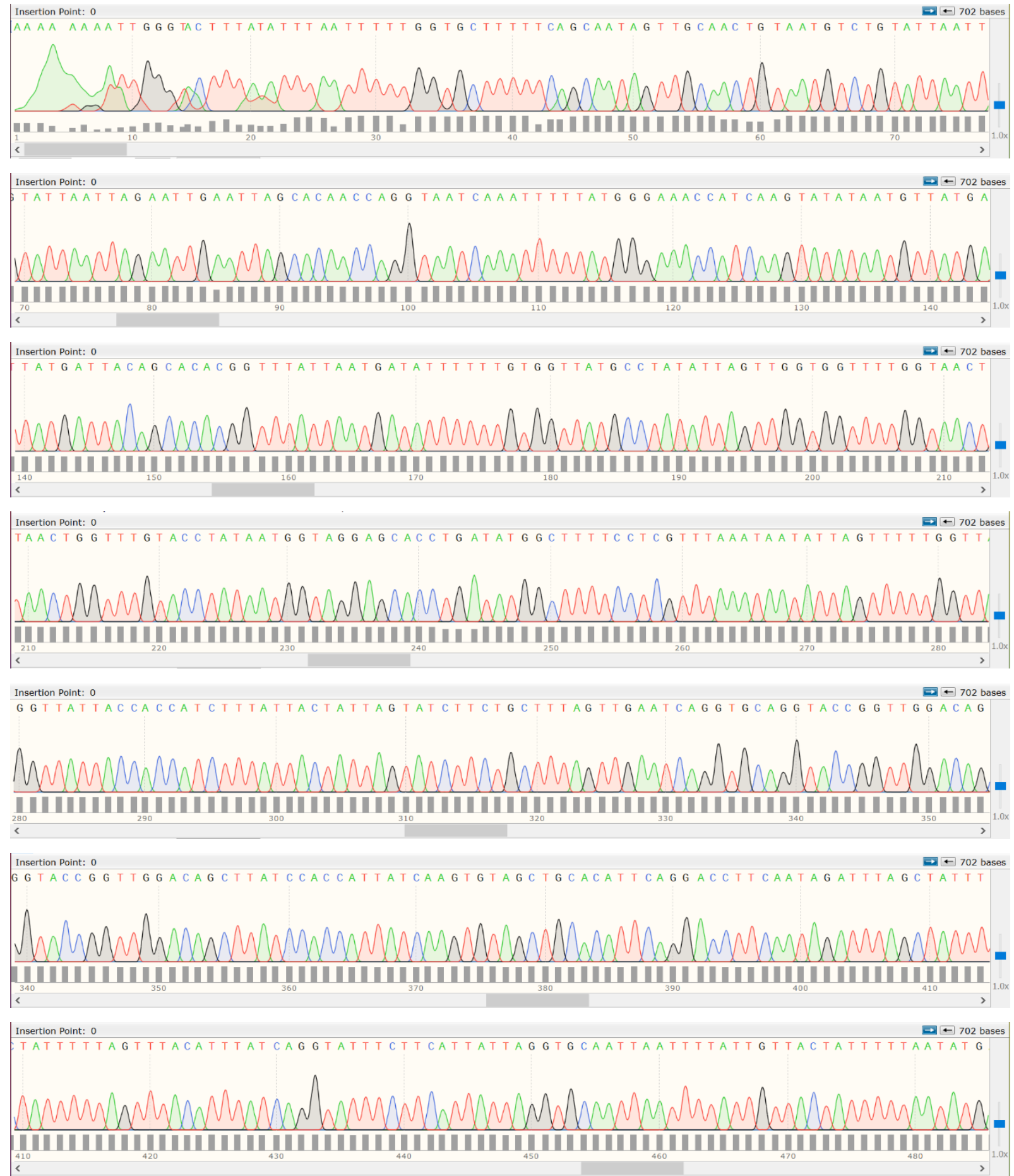


Insertion Point: 0

$\square \leftarrow 702$ bases

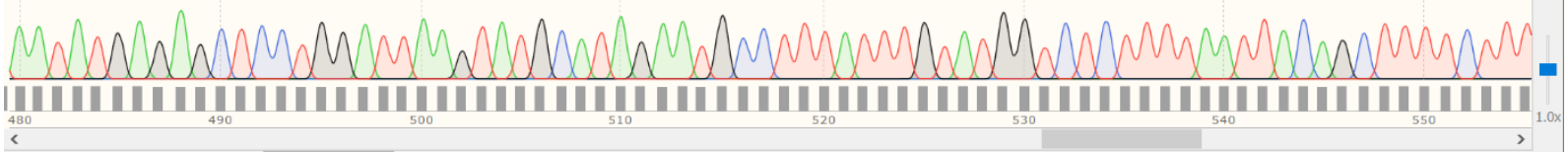

Insertion Point: 0
TT T C T T T T A G T T A T A A C T T T A C C A G T A T T T T C A G G T T C A A T A A C TA T G T T A T T A A C T G A T A G A A A T T T T A A T A C T T

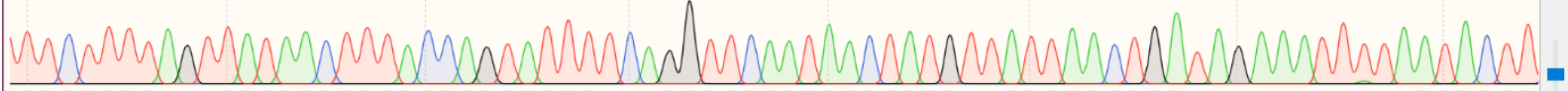

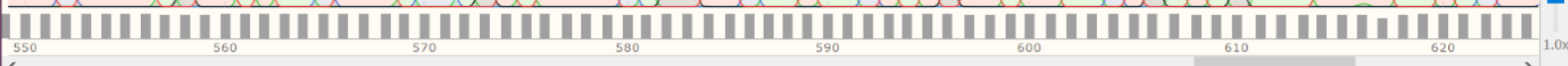

Insertion Point: 0

$\square \leftarrow 702$ bases

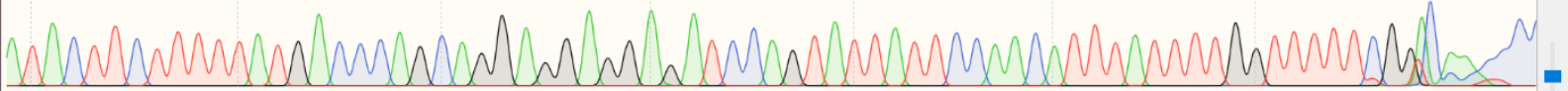

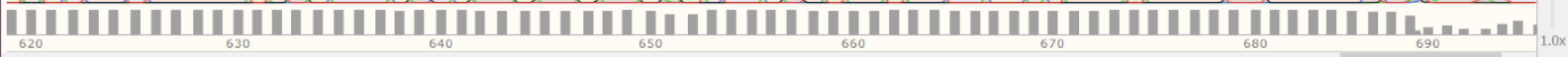

Insertion Point: 0

$\rightarrow \leftarrow 702$ bases

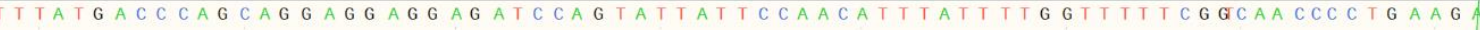

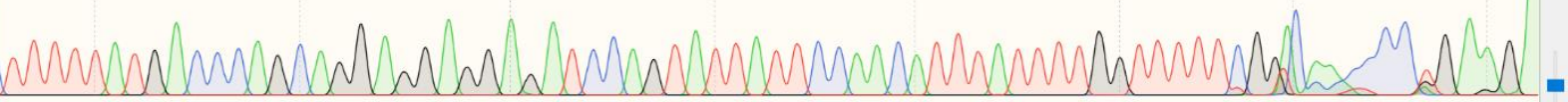

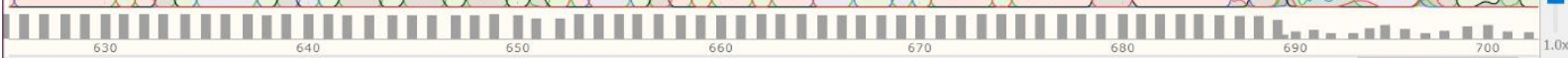

\section{A.2. Phổ giải trình tụ bằng mồi OomCoxI-levlo}

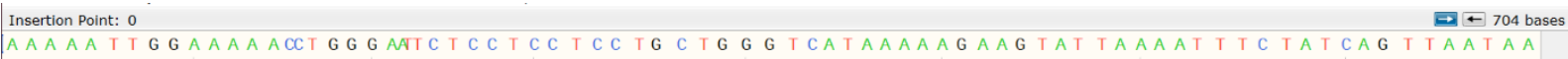

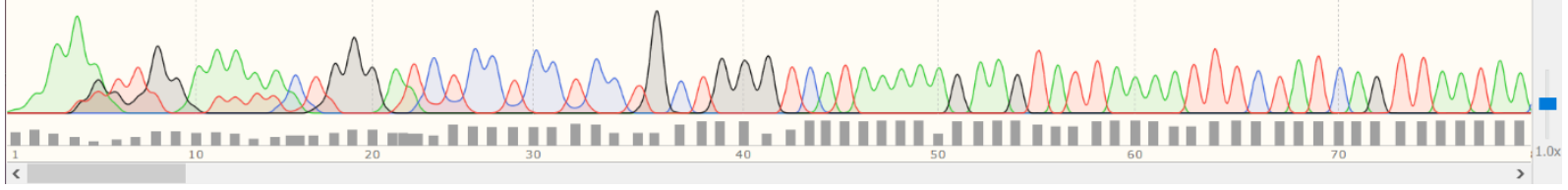

Insertion Point: 0
C A G T TA A T A A C A T A G T T AT T G A A C C T G A A A A T A C T G G T A A A G T T A T A A C TA A A A G A A A A G C T G T A A T T A A A A G

Insertion Point: 0
C A G T T A A T A A C A T A G T T A T T G A A C C T G A A A A T A C T G G T A A A G T T A T A A C T A A A A G A A A A G C T G T A A T T A A A A G

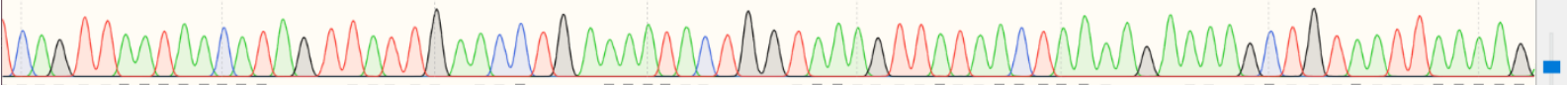

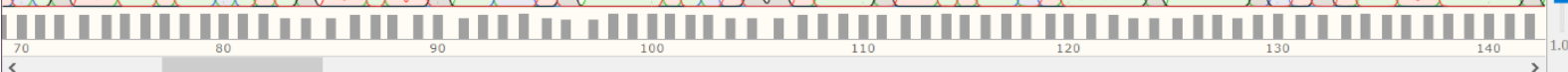

Insertion Point: 0

$\square \leftarrow 704$ bases

Insertion Point:

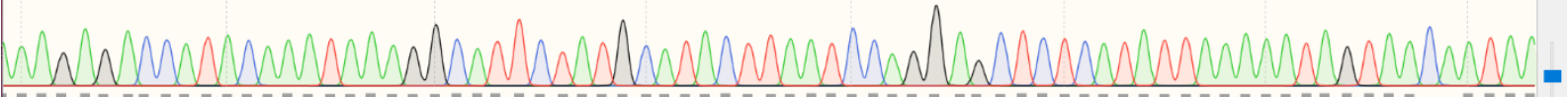

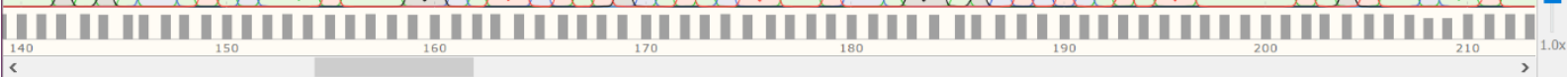

Insertion Point: 0

$\square \leftarrow 704$ bases A A TAA A A T TA A T T G CACC TAATAATGAAGAAATACCTGATAAATGTAAACTAAAAATAGCTAAATCTATTGAAGC

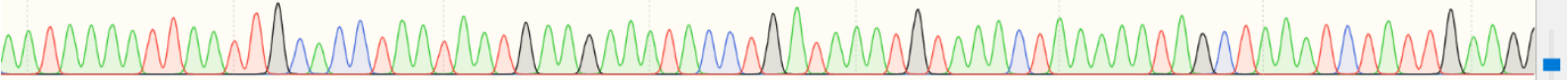

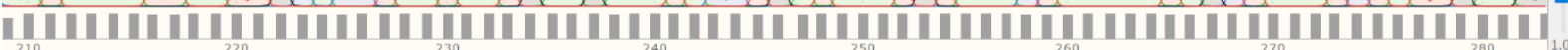




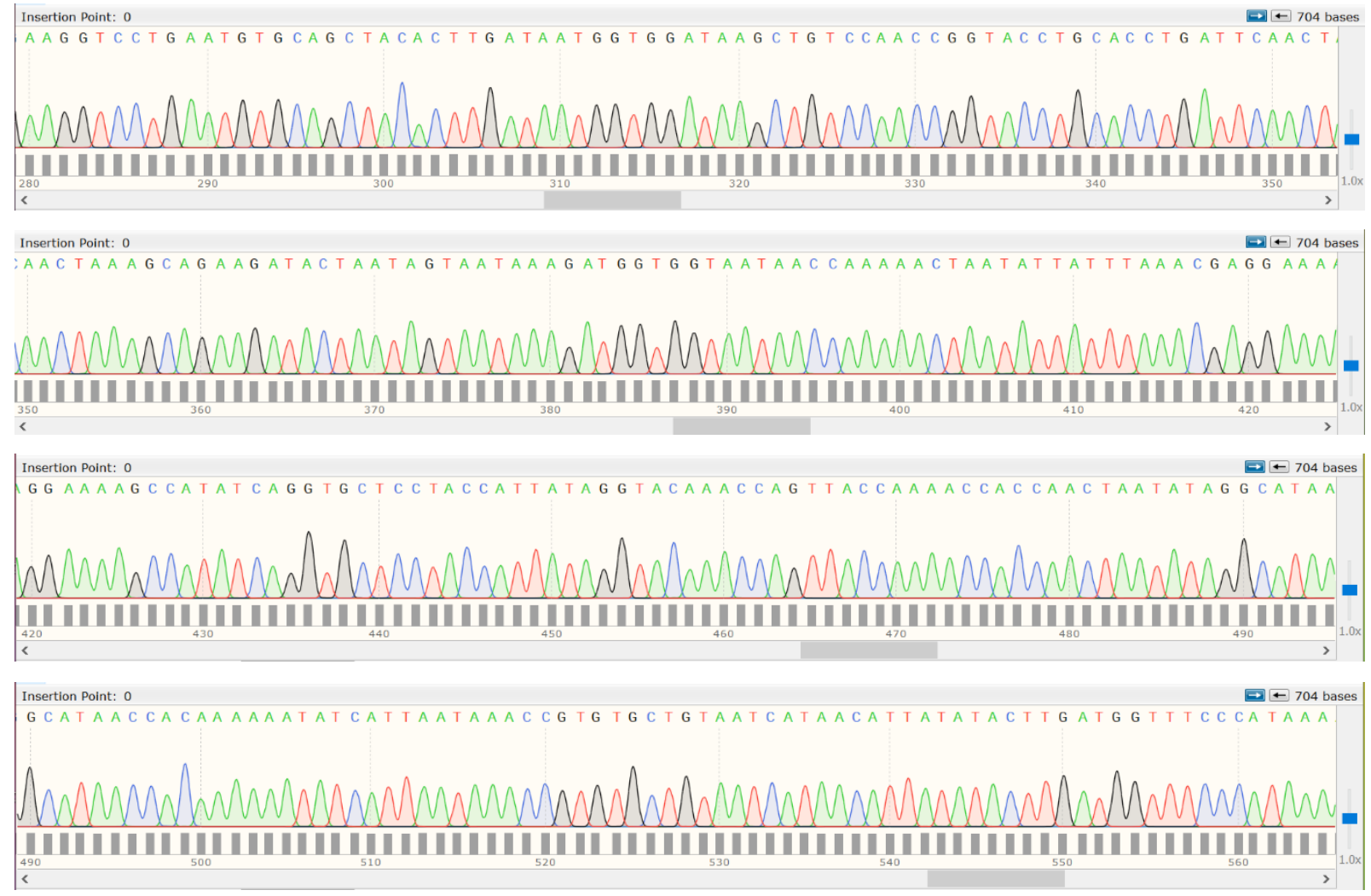

Insertion Point: 0

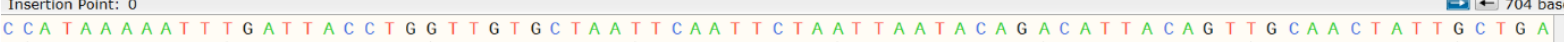

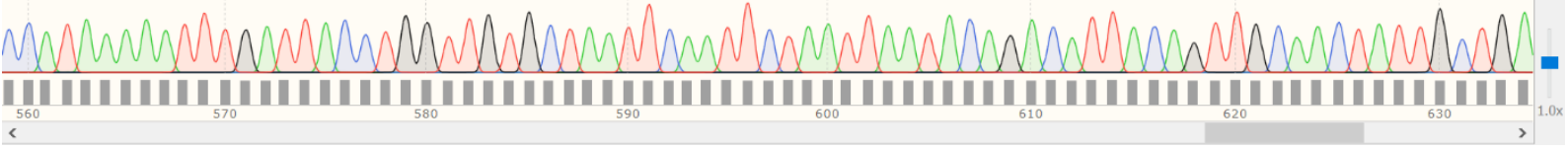
Insertion Point: 0 G C T G A A A A A G CAC CAAAA A T T A A A A

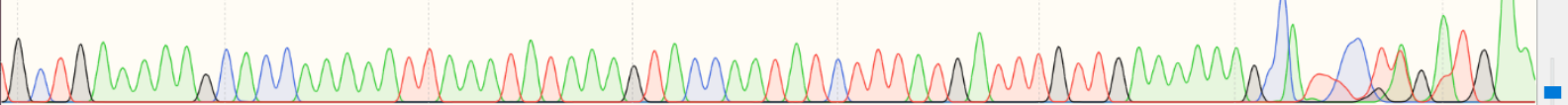

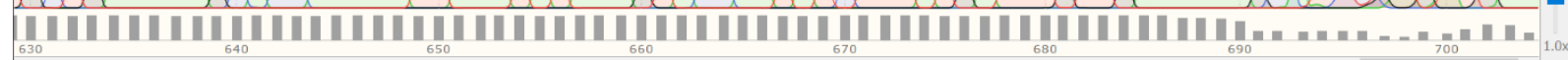

B. Kết quả phổ giải trình tự chủng LD5.4

B.1. Phổ giải trình tụ bằng mồi $20 F$

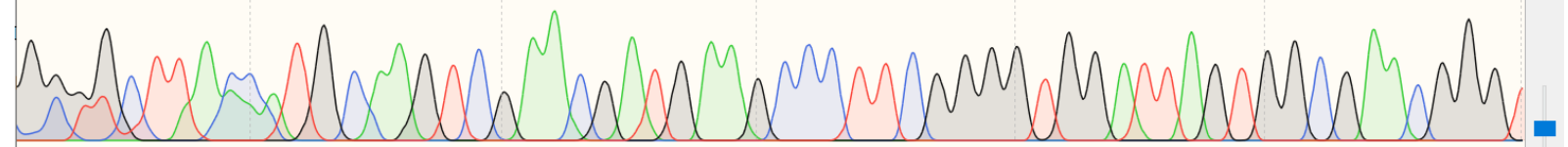

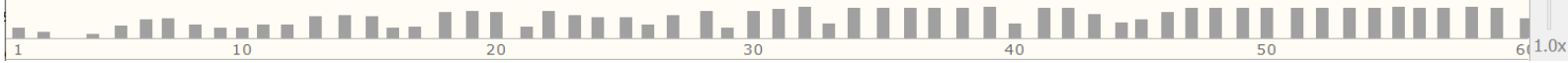


Insertion Point: 0

$\square \leftarrow 1198$ bases

T G A G T A AC A C G T G G G C A A T C T G C C C T T C A C T C T G G G A C A A G C C C T G G A A A C G G G G T C TA A

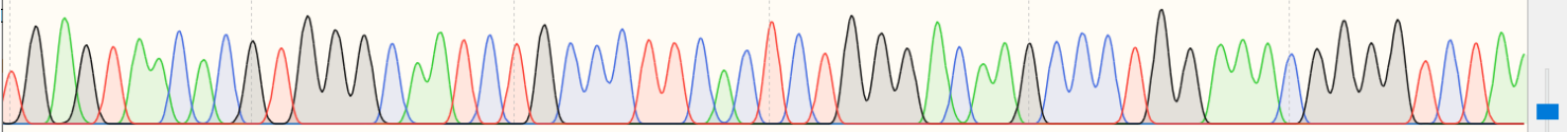
$\mathrm{s}_{0}$ $<$

Insertion Point: 0

$\square \leftarrow 1198$ bases

C G G G G T C TA A T A C C G G ATAC G A C T T G TCGA G G C A T C T T G A G G G G T G G A A A G C T C C G G C

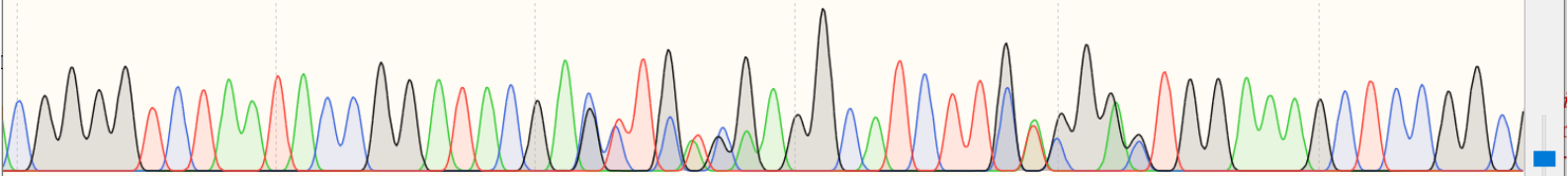

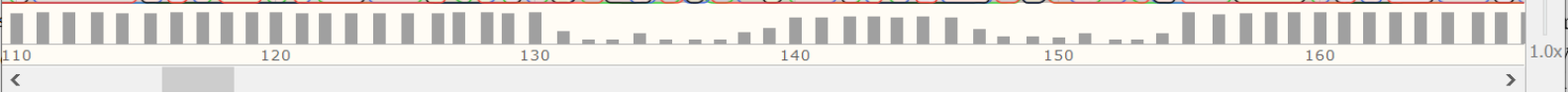

Insertion Point: 0

$\square \leftarrow 1198$ bases

G C T C C G G C G G T G A A G G A T G A G C C C G C G G C C T A T C A G C T T G T T G G T G G G G T A A C G G C C C A

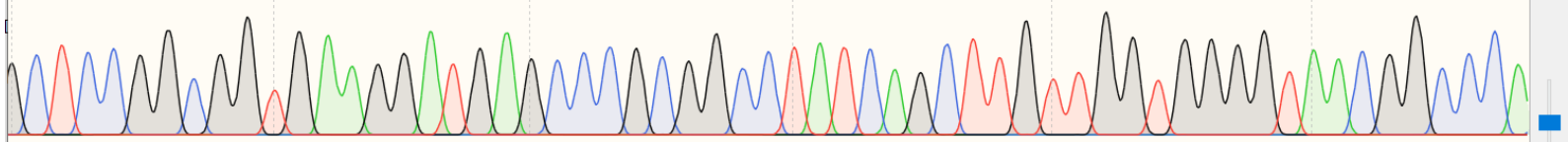
$\prod_{50}$

Insertion Point: 0

$\rightarrow \leftarrow 1198$ bases

TAACG GCC CAC CA A G G C G A C G A C G G G TA G C C G G C C T G A G A G G G C G A C C G G C C A C A C T G G

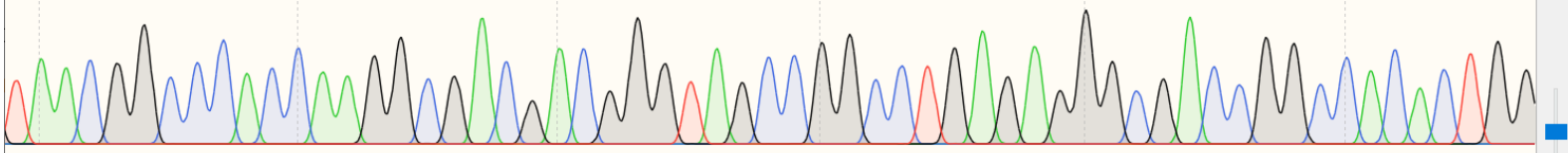
$\|_{210}$ $<$

Insertion Point: 0

$\rightarrow \leftarrow 1198$ bases

C A C A C T G G G A C T G A G ACACG GC C C A G A C T C C TACG G G A G G C A G C A G T G G G G A A T A T T G

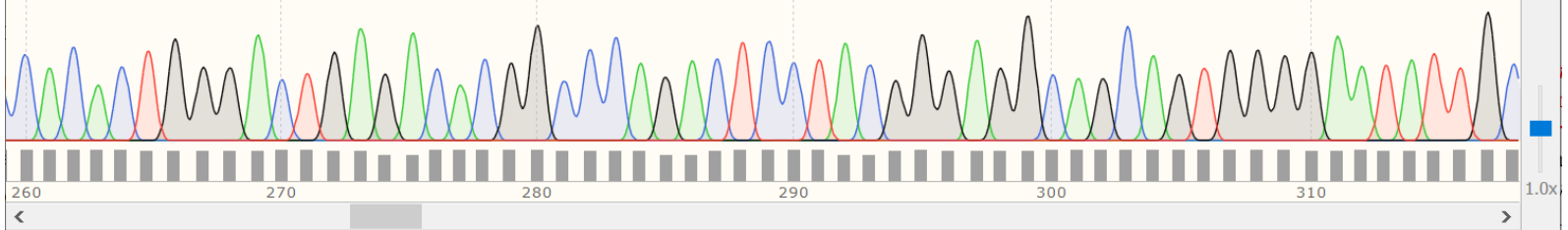

Insertion Point: 0

$\square \leftarrow 1198$ bases

G A A T A T T G C A C A A T G G G C G A A A G C C T G A T G C A G C G A C G C C G C G T G A G G G A T G A C G G C C T

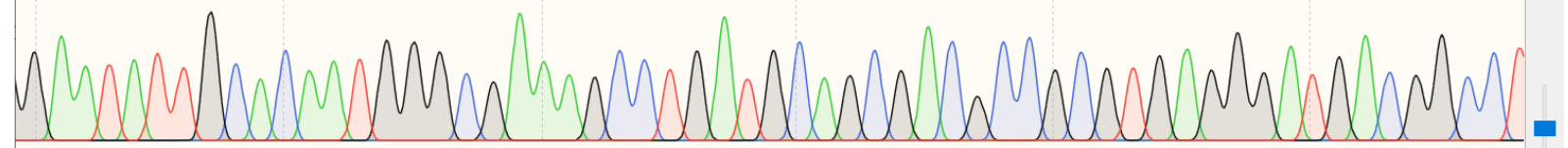

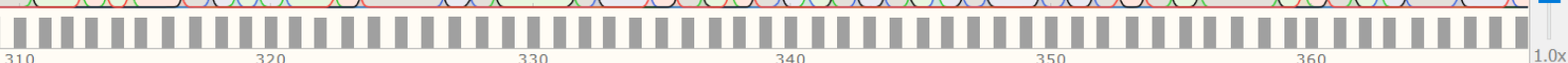



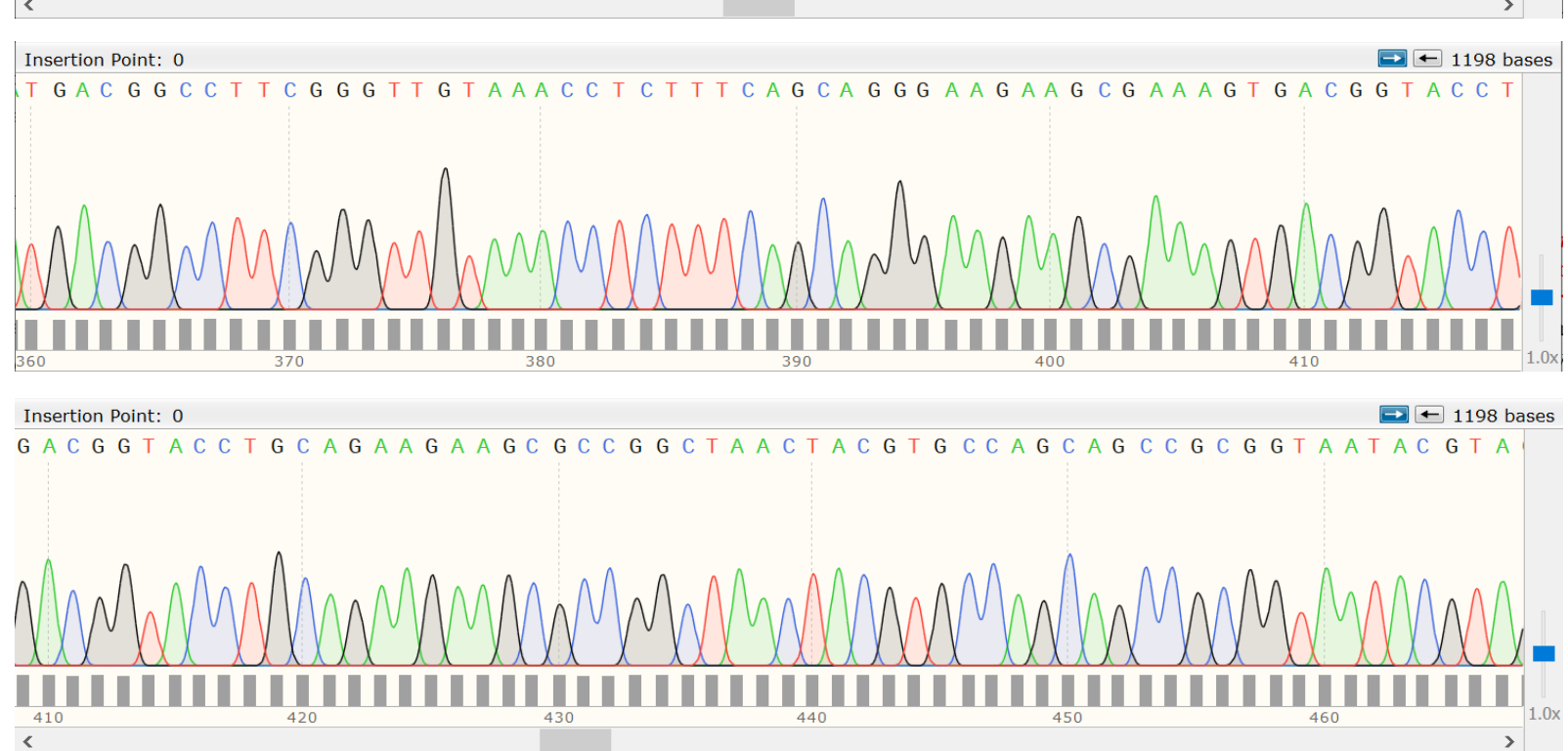

Insertion Point: 0

$\rightarrow \leftarrow 1198$ bases

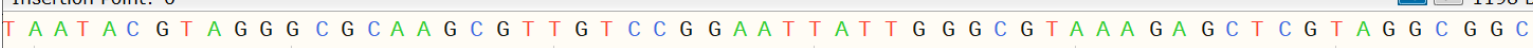

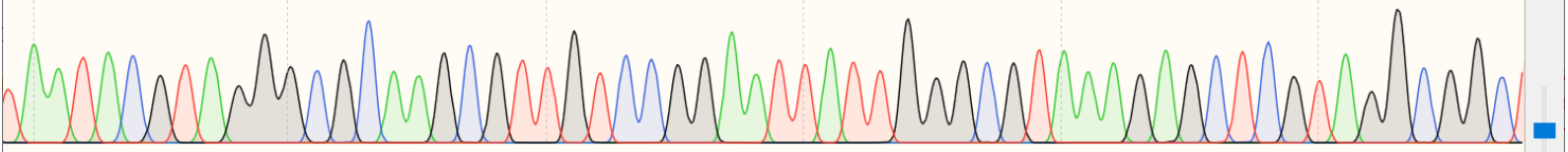
${ }_{460}$ 46

Insertion Point: 0

$\rightarrow \leftarrow 1198$ bases

T A G G C G G C T T G T C A C G T C G G G T G T G A A A G C C C G G G G C T T A A C C C C G G G T C T G C A T C C G A

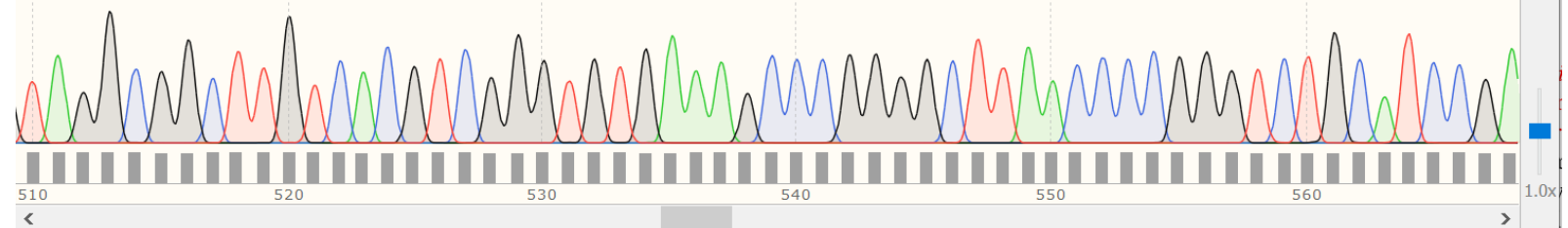

Insertion Point: 0

$\square \leftarrow 1198$ bases

T G G T G T G C G G T G A A A T G C G C A G A T A T C A G G A G G A A C A C C G G T G G C G A A G G C G G A T T C

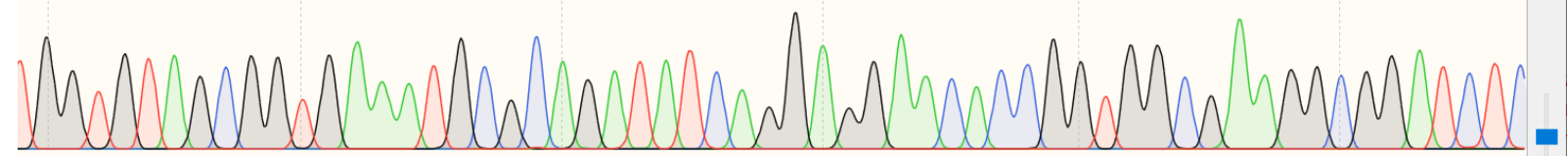

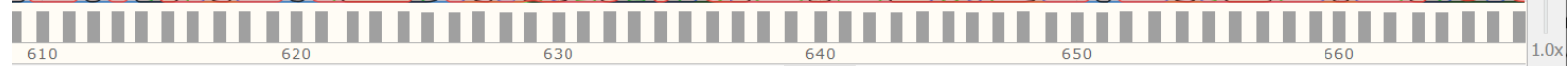


Insertion Point: 0

$\square \leftarrow 1198$ bases

$\therefore C G G A T C T C T G G G C C A T T A C T G A C G C T$ G A G G A G C G A A A G C G T G G G G A G C G A A C A G G A T T

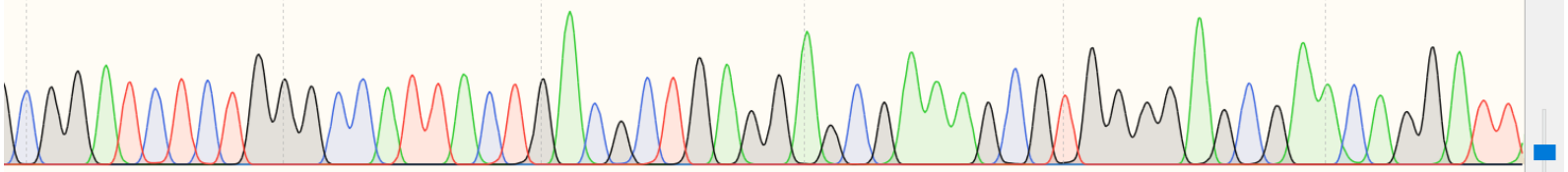

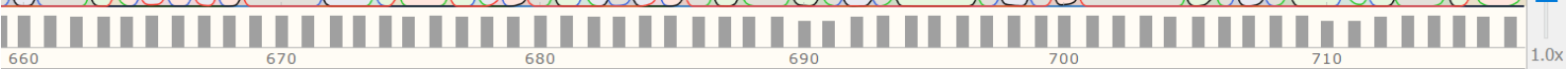

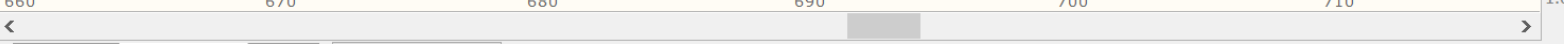

Insertion Point: 0

$\leftrightarrow \leftarrow 1198$ bases

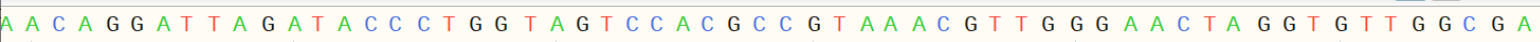

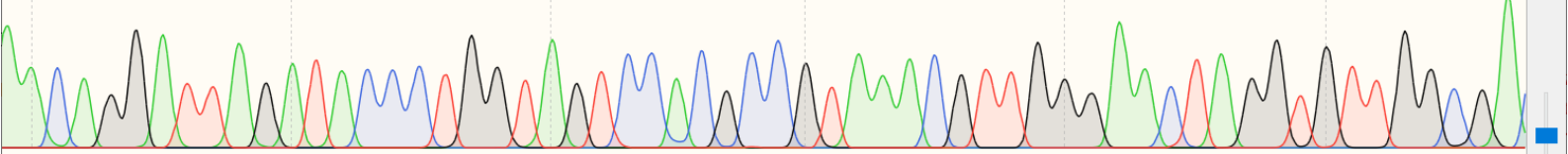

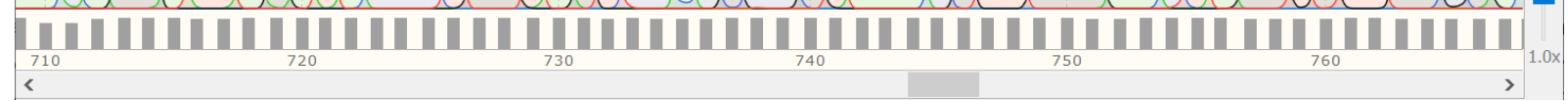

Insertion Point: 0

$\rightarrow \leftarrow 1198$ bases

T G T T G G C G A C A T T C C A C G T C G T C G G T G C C G C A G C T A A C G C A T T A A G T T C C C C G C C T G G G C

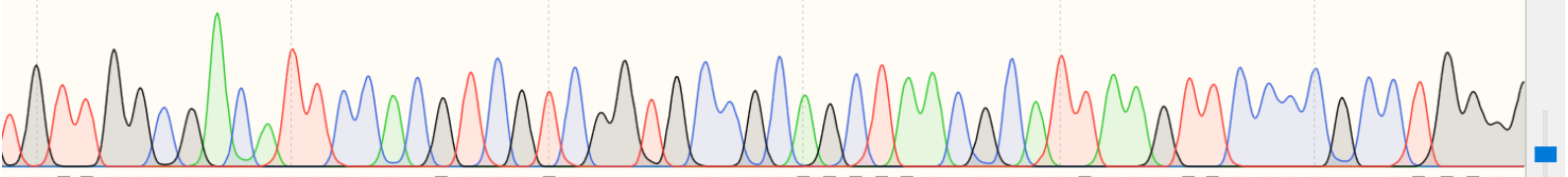
$<$

Insertion Point: 0

$\leftrightarrow \leftarrow 1198$ bases

C G C C T G G G G A G T C G G C C G C A A G G C TAAAAC T C A A A G G A A T T G A C G G G G G C C C G C A C A A

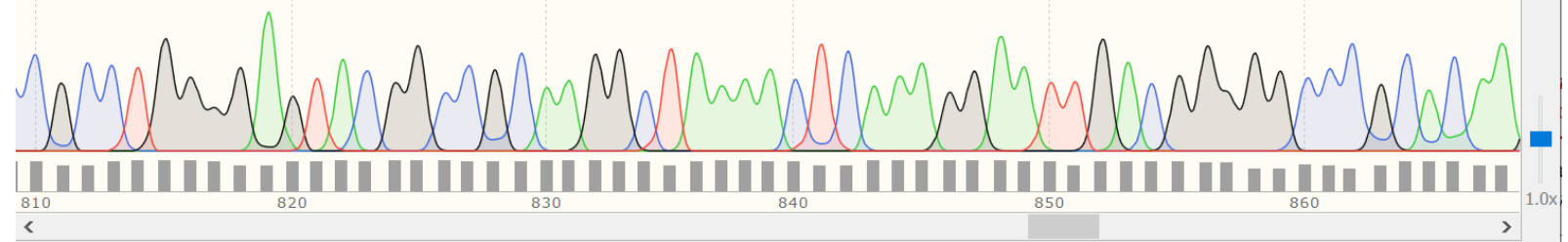

Insertion Point: 0

$\rightarrow \leftarrow 1198$ bases C C C G CACAA GCA G C G G A G C A T G T G G C T T A A T T C G A C G C A A C G C G A A G A A C C T T A C C A A G G

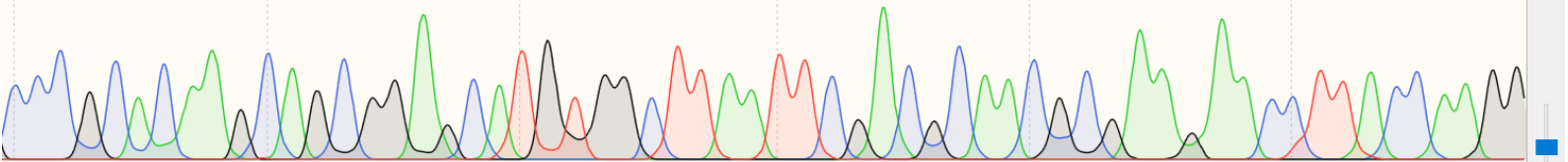
${ }_{360}$

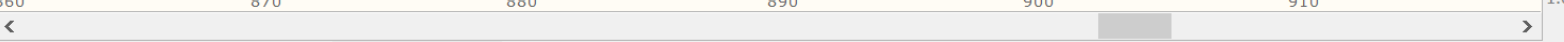
Insertion Point: 0 $\rightarrow \leftarrow 1198$ bases C C T T A C C A A G G C T T G ACA T A T A C C G G A A A G C G C C A G A G A T G G T G C C C C C C T T G T G G T C G G

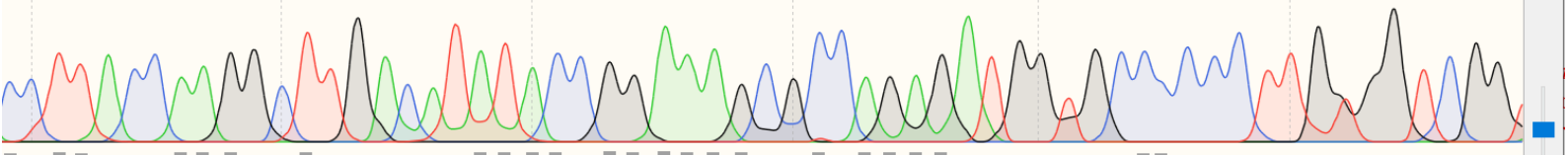
|| 
Insertion Point: 0

$\rightarrow \leftarrow 1198$ bases I T G T G T C G G TA TACA G G T G G G C A T G G C T G T C G T C A G C T C G T G T C G G G A G A T G T T G G T T

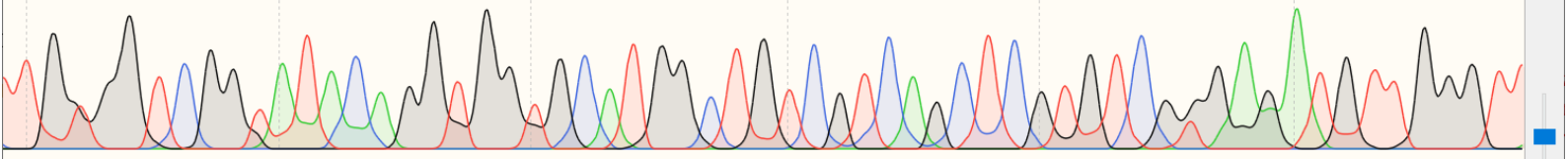

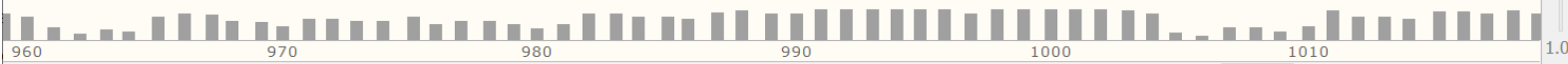
$<$

Insertion Point: 0

$\rightarrow \leftarrow 1198$ bases

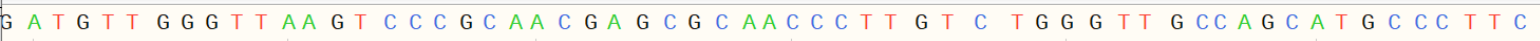

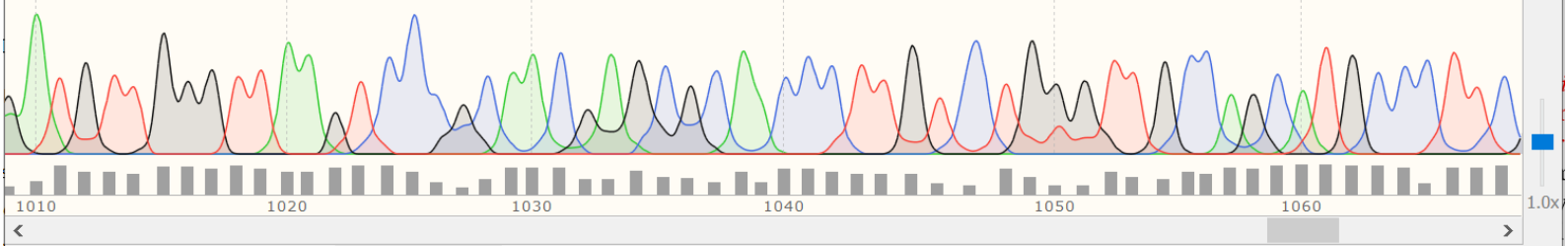

Insertion Point: 0

$\rightarrow \leftarrow 1198$ bases

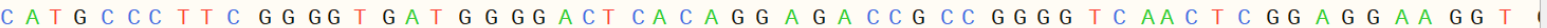
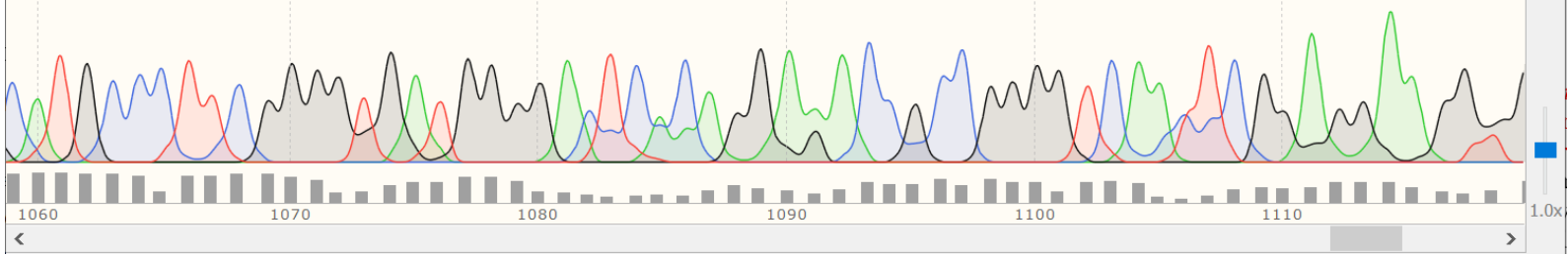

Insertion Point: 0

$\rightarrow \leftarrow 1198$ bases

G GG TCAAC T C G G A G G A A G G T G G G A C G A C G T C A A G TCATCA T G C C C C T T A T NN C T T G G G C T I

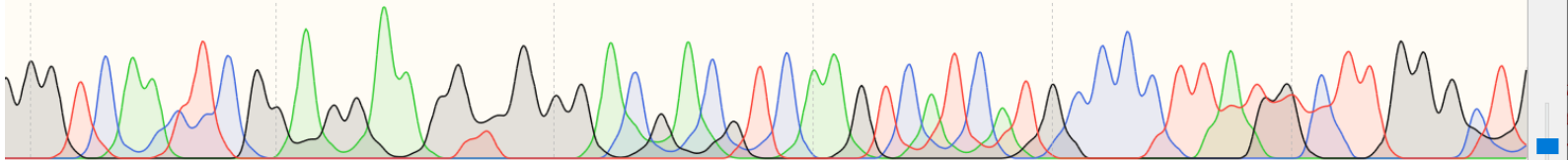

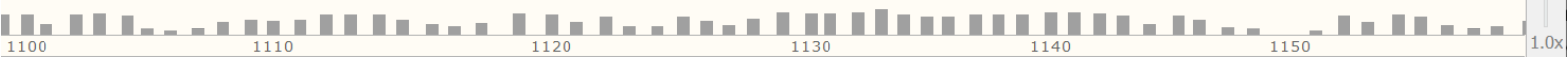
$<$

Insertion Point: 0

$\square \leftarrow 1198$ bases

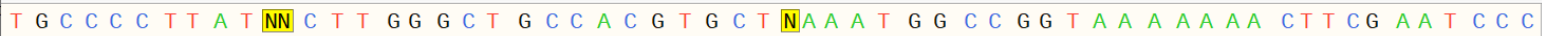

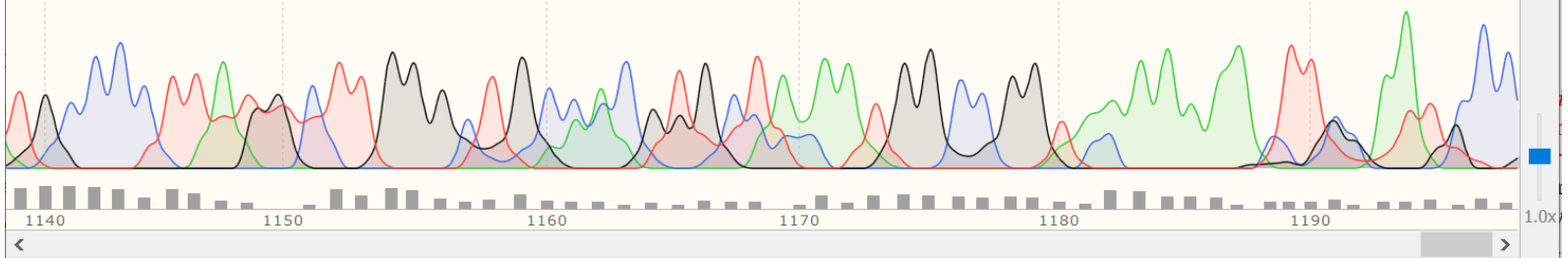

B.2. Phổ giải trình tụ bằng mồi $1500 R$

Insertion Point: $0 \quad$ 政 1270 bases GC C T G G T CAC C T T CG G G C T C C C C C C A G G G G T T G G GAC CACCG G C T T CG G G TG T TAC C G ACTT T CG TG ACG TGACC

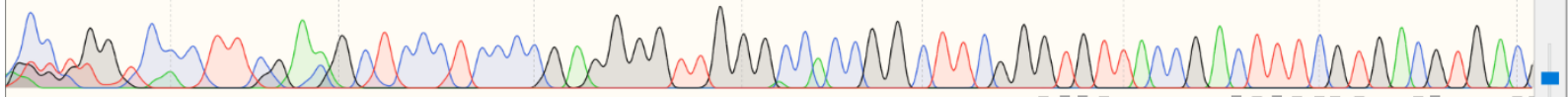

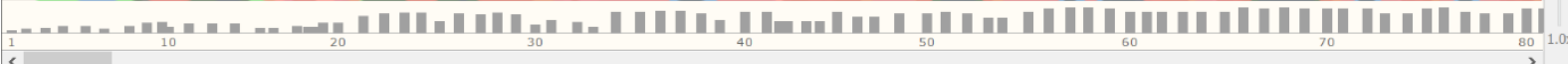




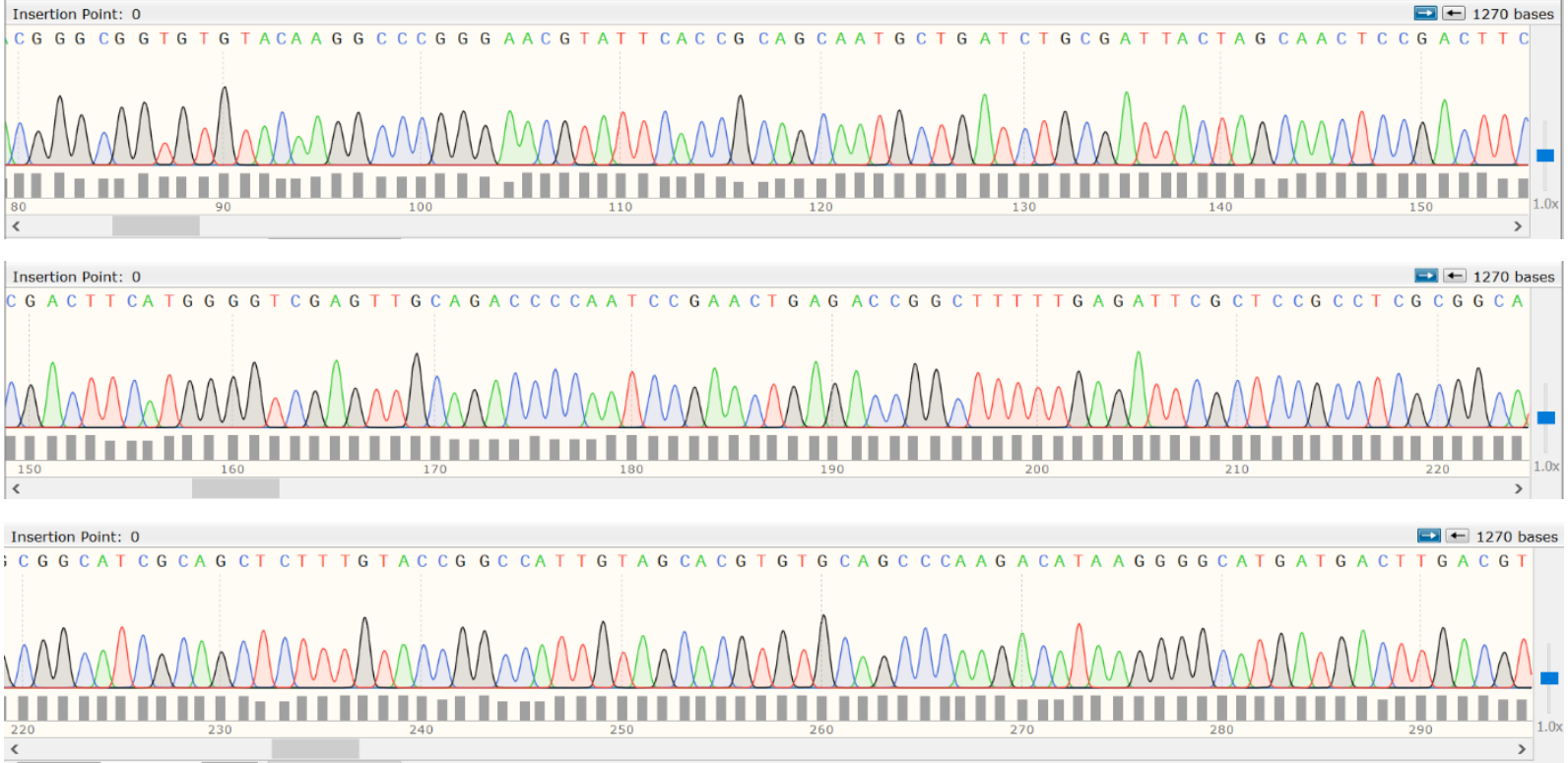

Insertion Point: 0
T T G A C G T C G T C C C CA C C T T C C T C C G AG TT G A C C C C G G C G G T C T C C T G T G A G T C C C CA T C A C C C C G A A G G G C A T G C T G

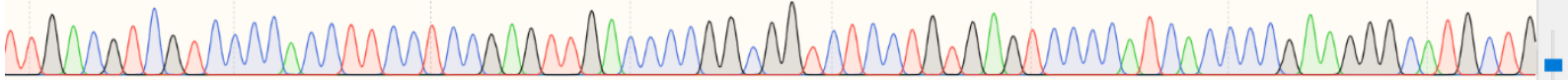

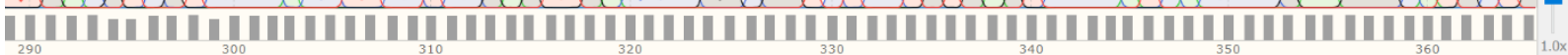

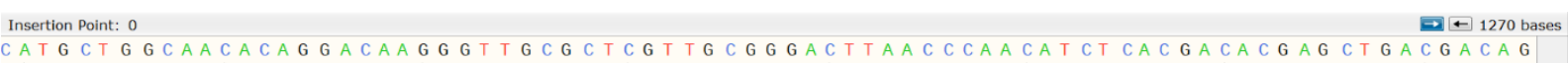

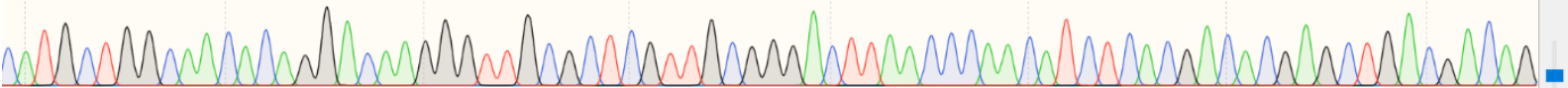

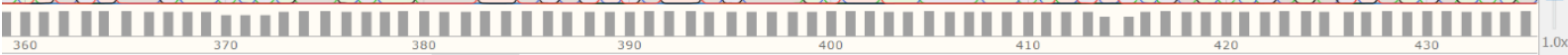
Insertion Point: 0
A C GACA G C CATG CA C CA C C T G TA A A C C G A C CA CAAG G G G G G C A C C A T C T C T G G C G C T T T C C G G T A T A T G T CA A G C C T T

whom:

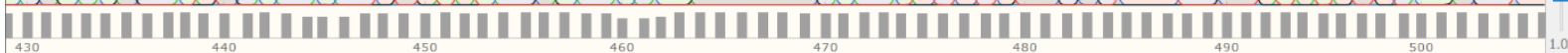
Insertion Point: 0
C A A G C C T T G GT A A G G T T C T T C G C G T T G C G T C G A A T T A A G C CA C A T G C T C C G C T G C T T G T G C G G G C C C C C G T C A A T T C

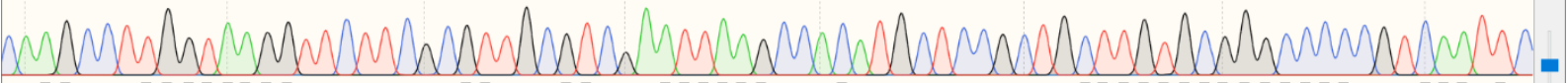

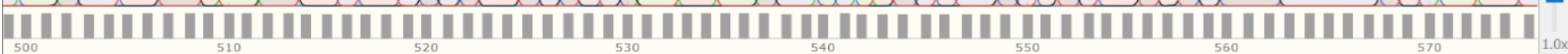

Insertion Point: $0 \quad 0 \quad \Leftrightarrow \leftarrow 1270$ bases

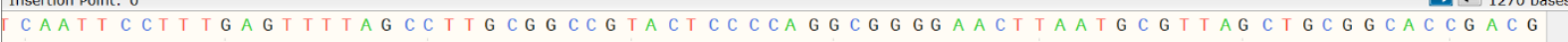

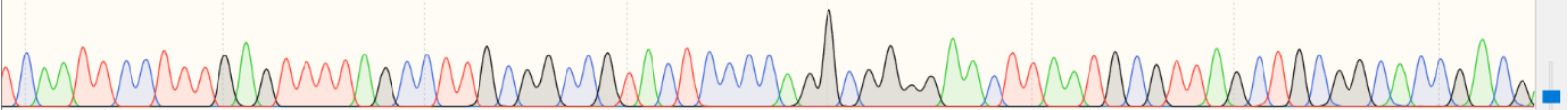

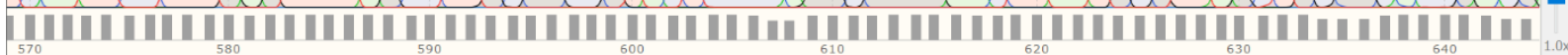

Insertion Point: $0 \quad$ 国 $\leftarrow 1270$ bases C CGACGACGTGGAATGTCGCCAACACCTAGTTCCCAACGTTTACGGCGTGGACTACCAGGGTATCTAATCCTGTTC

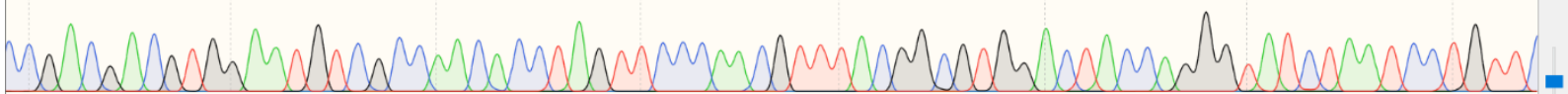

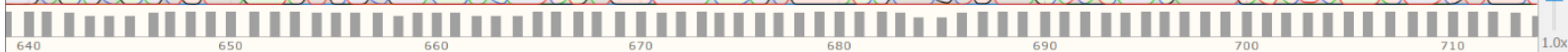




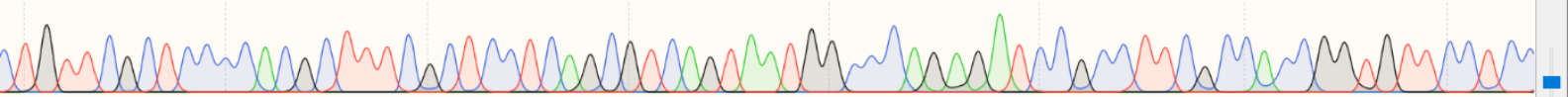

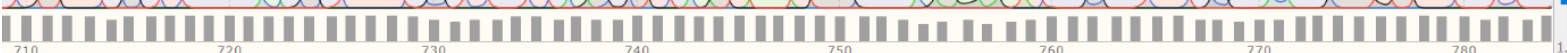

Insertion Point: 0

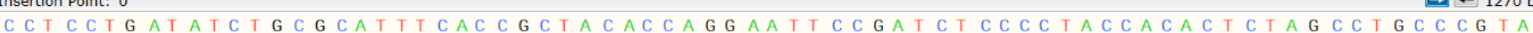

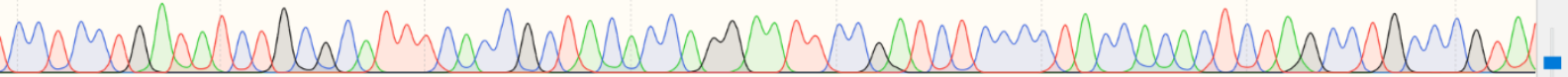

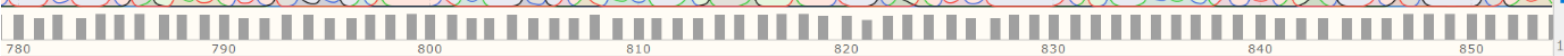

$\square \leftarrow 1270$ bases

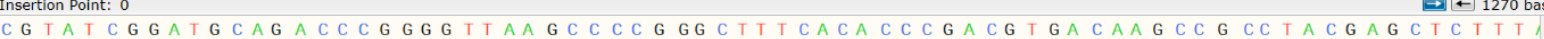

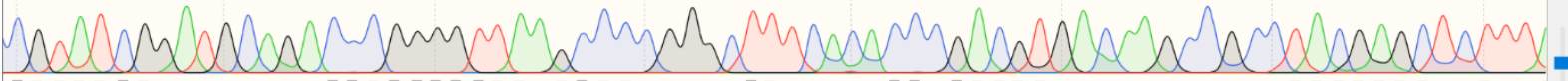

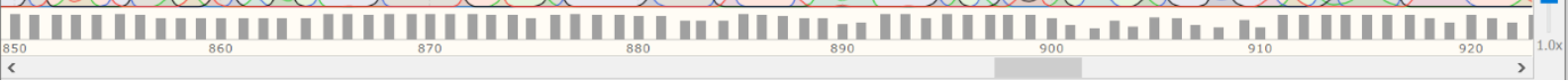

Insertion Point: $0 \quad$ 且 $\leftarrow 1270$ bases TTTACGCC CAATAATTCCGGACAACGCTTGCGCCCTACGTATTACCGCGGCTGCTGGCACGTAGTTAGC C GGC

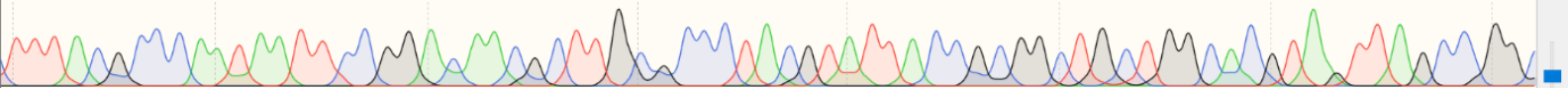

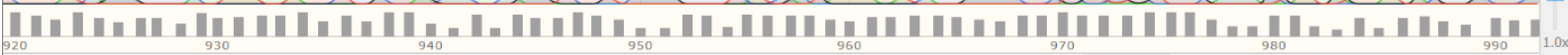
920
$<$

Insertion Point: 0

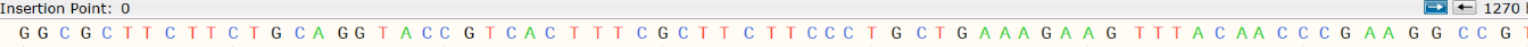

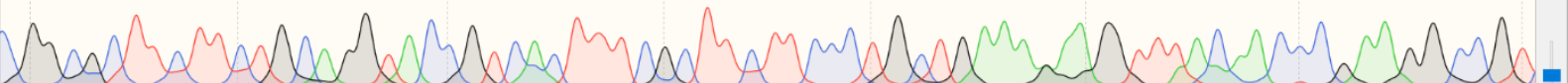

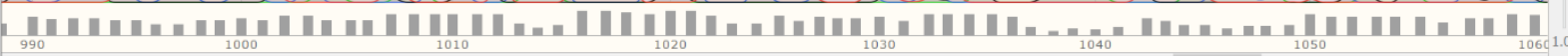

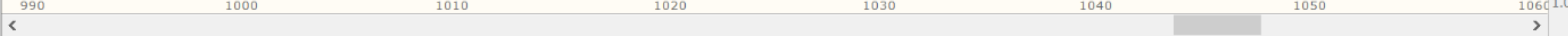

Insertion Point: 0

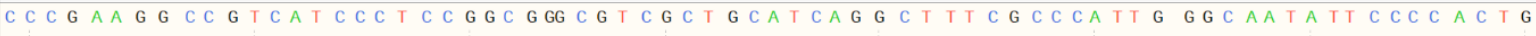

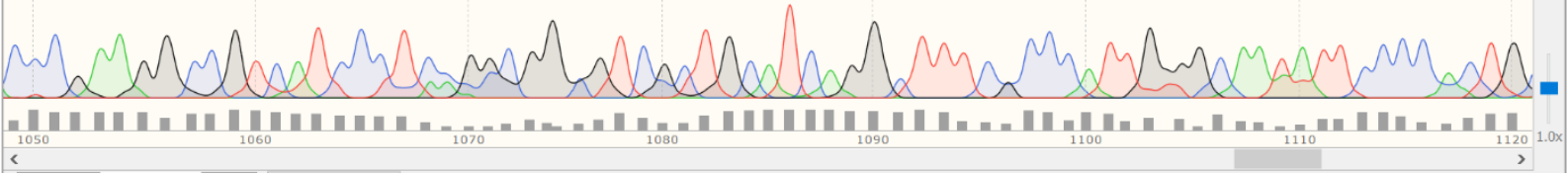

Insertion Point: $0 \quad \square \leftarrow 1270$ bases

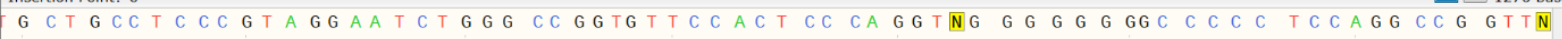
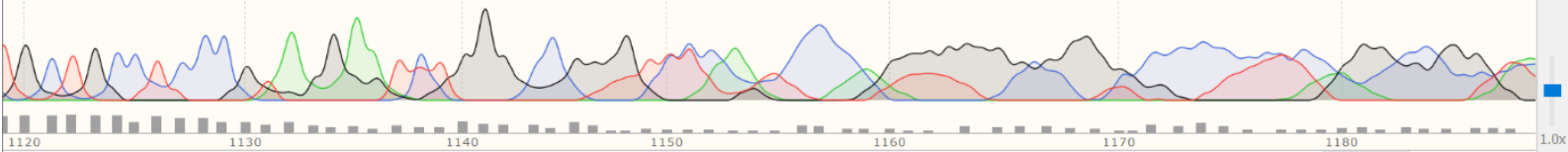

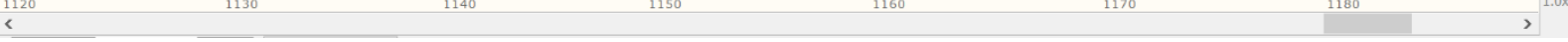

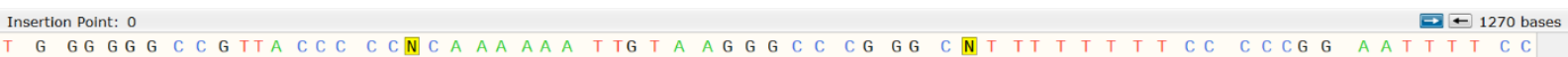

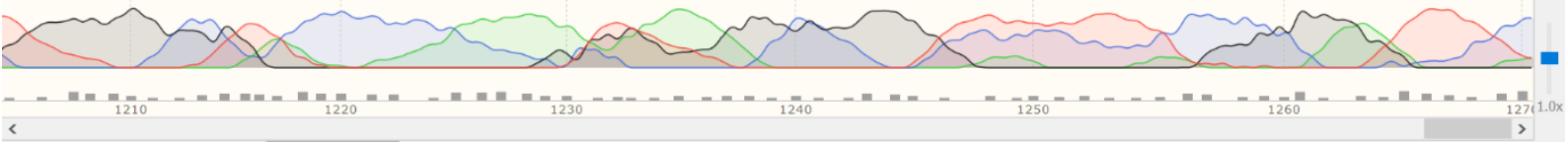

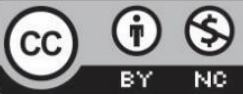

Creative Commons Attribution-NonCommercial 4.0 International License. 